\title{
La materialidad de la muerte en la necrópolis de Baelo Claudia. Ritos y creencias en contexto
}

\section{The materiality of death in the necropolis of Baelo Claudia. Rites and beliefs in context}

\author{
Fernando Prados Martínez \\ Instituto Universitario de Investigación en Arqueología y Patrimonio Histórico \\ Universidad de Alicante, \\ Helena Jiménez Vialás ${ }^{2}$ \\ CNRS Université de Toulouse, TRACES-UMR 5608
}

\section{RESUMEN}

En este artículo se presentan las últimas novedades de las excavaciones en la necrópolis hispanorromana de Baelo Claudia (Tarifa, Cádiz). En paralelo, junto con documentación arqueológica inédita, se realiza una reflexión general sobre la importancia del análisis contextual en el caso de las necrópolis que, por encima de aproximaciones teóricas, se apoya en la materialidad de las distintas prácticas funerarias. Toda interpretación, indefectiblemente abierta a debate, deberá apoyarse en un escrupuloso trabajo de campo que tenga en cuenta las particularidades de este registro y la dificultad de su documentación.

\section{SUMMARY}

In this paper, we present the new results of our archaeological works in the Necropolis of Hispano-Roman Baelo Claudia (Tarifa, Cadiz). Based on both archaeological excavations and theoretical interpretations, we will discuss about the materiality of rituals and beliefs through the analysis of objects and contexts. Our final aim is to emphasize the value of renewed archeological fieldwork as a way of build new data and interpretations.

PALABRAS CLAVE: Estrecho de Gibraltar; hispanorromano; estratigrafía; prácticas funerarias; ritual.

KEY WORDS: Strait of Gibraltar; Hispano-Roman; Stratigraphy; funerary practices; ritual.

\section{BAELO CLAUDIA EN EL CENTRO DEL DEBATE SOBRE LA ROMANIZACIÓN. UN LABORATO- RIO DE ESTUDIO IMPRESCINDIBLE ${ }^{3}$}

La ciudad hispanorromana de Baelo Claudia (Tarifa, Cádiz) se emplaza en un lugar estratégico como es el estrecho de Gibraltar, una zona permeable y dinámica desde el punto de vista histórico y cultural (Fig. 1). Baelo, que puede presumir de haber sido objeto de investigaciones durante más de un siglo, se ha convertido en un magnífico laboratorio de estudio, tanto por ser centro de múltiples intervenciones y proyectos científicos, como por su magnífico estado de conservación. La enorme potencialidad de la ciudad y de sus necrópolis ha sido valorada en numerosas ocasiones, sobre todo a la hora de analizar su desarrollo a escala regional, y ha servido de base para ascender a las escarpadas cumbres de la teoría arqueológica, desde las tesis más tradicionales de orientación colonialista a los más recientes estudios post-coloniales; ha servido, por tanto, de ejemplo para abordar algunos de los diversos fenómenos que englobamos bajo el nombre de "romanización", como la adopción de modelos urbanísticos romanos, la construcción de nuevas identidades o la etnogénesis, así como las perduraciones del sustrato cultural previo a Roma (Paris et alii 1926; Remesal 1979; Sillières 1997; Bendala 2002 y 2010; Jiménez 2002 y 2008;

\footnotetext{
${ }^{3}$ Este artículo se realizó durante una estancia en la Faculty of Classics de la University of Oxford financiada por el Ministerio de Educación, Cultura y Deporte en el marco del Programa "José Castillejo" del Plan Estatal de Investigación Científica y Técnica y de Innovación 2013-2016.
}

\footnotetext{
${ }^{1}$ fernando.prados@ua.es

${ }^{2}$ helenavialas@gmail.com
} 


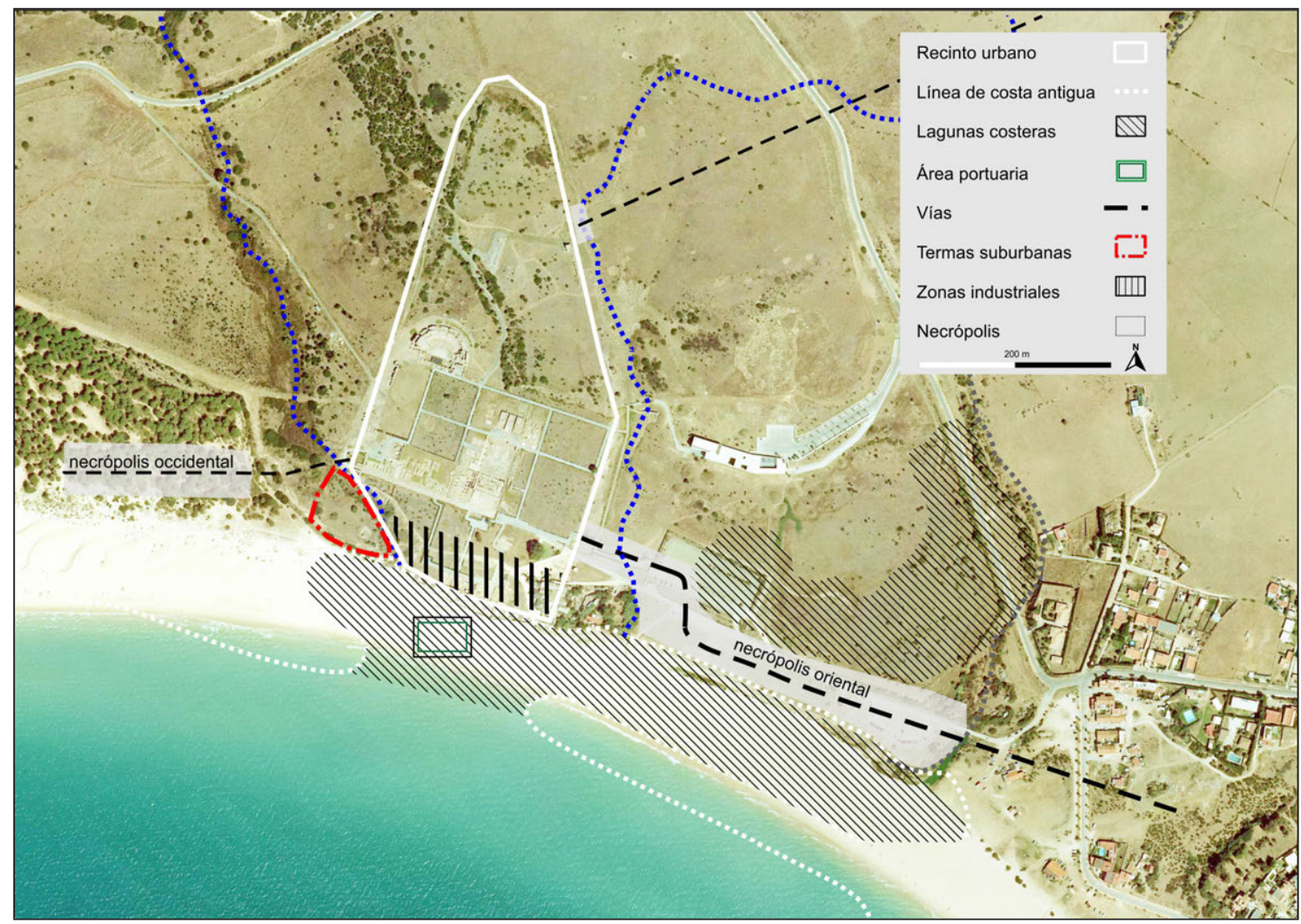

Figura 1. Baelo Claudia y su área periurbana. Imagen MBC y PNOA-IGN.

Vaquerizo 2010 y 2013; Prados 2011 y 2015b; Prados et alii 2014, entre otros).

Tanto el espléndido conjunto urbano, en el que destaca por su óptimo estado de conservación el área del foro, con su imponente conjunto de templos y su basílica, como las termas, el macellum, el trazado viario, la factoría de salazones o la muralla, pero igualmente el área periurbana donde se han excavado recientemente unas termas "marítimas" desconocidas, y donde se sitúa la necrópolis oriental objeto de este trabajo, han servido para plantear durante los últimos cien años numerosas hipótesis, constructos históricos de diversa índole y publicar un sinfín de trabajos de referencia sobre el urbanismo, la economía o la religión, así como otros más específicos sobre las factorías de salazones, el teatro, los templos, la epigrafía, las necrópolis o el paisaje (Sillières 1997; Bonneville et alii 2000; Dardaine et alii 2007; Arévalo y Bernal 2007).

Desde 2009 un equipo coordinado por los aquí firmantes han centrado sus estudios en la necrópolis oriental que, desde las profusas excavaciones desarrolladas por P. Paris y G. Bonsor entre 1917 y 1921, apenas habían sido objeto de atención, a excepción de campañas puntuales como las llevadas a cabo por A. Bourgeois y M. del Amo en 1969 o las de J. Remesal, entre 1972 y 1974 (Paris et alii 1926; Bourgeois y del Amo 1970; Remesal 1979). Nuestro objetivo de partida fue la recuperación de los viejos trabajos, la indagación en las antiguas lecturas, efectuadas desde métodos y posicionamientos teóricos tan alejados de los recientes, pero que han sido fundamentales para construir unos cimientos sobre los que levantar nuevas propuestas. En esas nuevas "viejas" lecturas, hemos encontrado un volumen de información clave para alcanzar nuevos horizontes interpretativos, así como la confirmación de la calidad de lo hecho y publicado, a excepción de algunos aspectos a todas luces insalvables por el escaso interés en documentar contextos estratigráficos en la primera mitad del s. $\mathrm{xx}$, o a la irreparable - aunque justificada por los años transcurridos - pérdida de documentación y de materiales provenientes de las antiguas campañas.

Junto con ese trabajo de pesquisa historiográfica, unido a la digitalización de imágenes y planos, se han planteado nuevas intervenciones arqueológicas, para revestir de actualidad estratigráfica y de contexto todo ese volumen de información (Prados y Jiménez 
2015). Estas nuevas actuaciones han documentado sepulcros inéditos que han sido lógicamente exhumados atendiendo a la metodología actual de excavación, registro y conservación (Fig. 2).

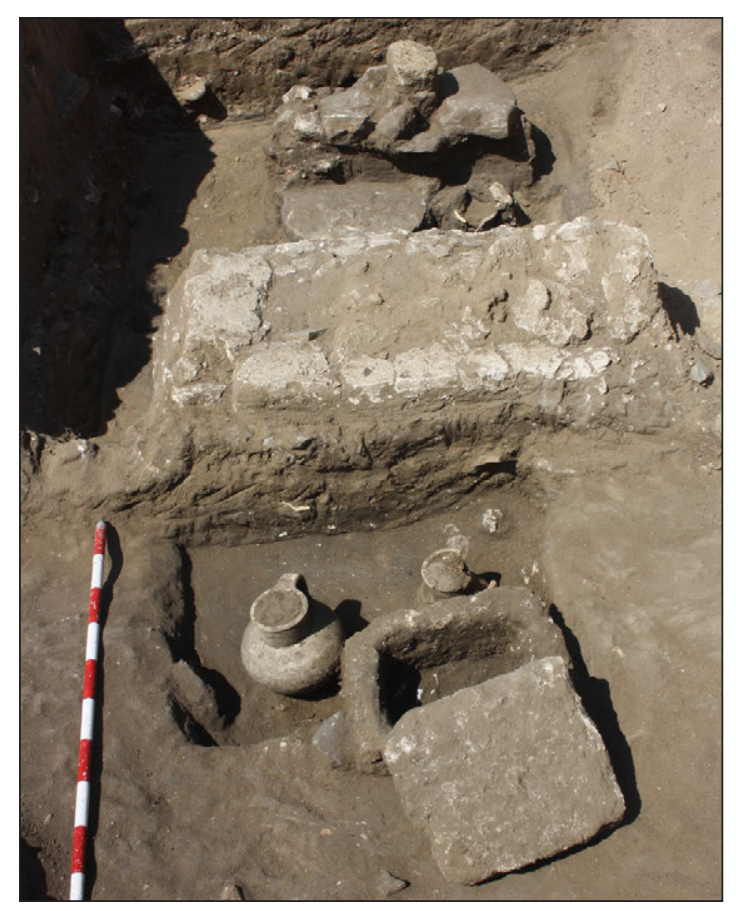

Figura 2. Enterramientos de cremación en urna de piedra y cupa de Baelo Claudia. Campaña de 2012.

Es por ello que queremos, a través de estas líneas, poner el acento sobre la importancia de la contextualización arqueológica, a través de los sistemas de excavación y registro, como única forma de alcanzar lecturas plausibles, alejadas necesariamente del relativismo a veces imperante en nuestra disciplina, enmascarado bajo la capa de la posmodernidad (Nilsson-Stutz y Tarlow 2013). No por una excesiva prudencia hemos de renunciar a tratar de ser resolutivos, sabiendo que para el caso funerario nos movemos en los tortuosos terrenos de la interpretación y de la ideología del arqueólogo responsable. Excavación, registro/documentación y descripción serán la única base para ulteriores interpretaciones, estas sí indefectiblemente efímeras.

Valga este texto como llamada a la necesidad de la comprobación empírica, a pie de campo, de los posicionamientos teóricos — nada desdeñables—, por otro lado, pero que necesitan de una materialidad a la que a día de hoy sólo se puede arribar desde el trabajo de campo, no necesariamente, pero sí desarrollado in situ. Si el fin último es alcanzar un mayor índice de conocimiento y de objetividad, hemos de acudir a ese juicio pertrechados de todas las herramientas posibles. La naturaleza de esta compleja necrópolis, reflejo nítido de una sociedad mixta y cambiante, como veremos, sólo puede ser reconocida sobre el terreno, observando todos y cada uno de los indicios, hasta los detalles más nimios: desde un pequeño amuleto, hasta los más llamativos, como su organización "urbana" y su posición en relación con la ciudad y con el entorno, pasando por sus fases, sus monumentos y su contexto socio-histórico.

\section{EL CONTEXTO EN ARQUEOLOGÍA FUNE- RARIA. MÁS ALLÁ DE LA EXCAVACIÓN ARQUEOLÓGICA}

La Arqueología de la Muerte tiene como objetivo restituir el comportamiento de las sociedades del pasado de cara a la muerte y, particularmente, de cara al cadáver. Se trata, por lo tanto, de una arqueología que estudia los "gestos" funerarios. La Arqueología hace hablar a esos elementos que se documentan en una deposición funeraria, siendo necesariamente el "objeto biológico" —el cadáver-, el más importante y que suele centrar el interés del investigador (Roberts 2013: 89). Pero serán los objetos propios del ajuar, de los ritos o de las ofrendas, su selección, su forma y, sobre todo, su ubicación dentro del depósito, relacionados entre sí y con el "objeto biológico", los que deberán completar la información que irremediablemente se omite en el análisis forense. El estudio contextual, pues, nos acerca al conocimiento del espacio en el que se encuentran todas las evidencias, y estas se pueden interpretar, precisamente, gracias a su posición en ese espacio y a la relación existente entre ellas.

"The object's meaning is the effects it has on the world..." A partir de esta elocuente apreciación de I. Hodder, en la introducción a la obra en que analiza contextualmente los significados simbólicos (Hodder 1987: 1), se refleja un hecho evidente, pero tantas veces soslayado: el contexto va más allá de la relación de los objetos con su espacio físico o social. Y es que los objetos pueden tener diversos significados: podemos hablar de cómo se emplearon, lo que nos informa sobre las características sociales, los sentimientos personales y las creencias religiosas de los usuarios; también podemos analizarlos a partir de sus características tecnológicas y también desde su morfología. Lo evidente es que los objetos forman parte de códigos que desde la Arqueología deberíamos poder descifrar. Pensamos que las excavaciones de la necrópolis de Baelo han de ser clave para aprovechar esa información que proporcionan los objetos, siempre 
que estos se encuentren en contexto (estratigráfico y cultural) y que permitan vislumbrar sus efectos: quizás así podamos reconocer los fenómenos de perduración cultural y de renovación que la sociedad de esta pequeña ciudad del Estrecho disfrutó tras una paulatina romanización (Bendala 2015).

Al investigar arqueológicamente una necrópolis como la de Baelo, en el marco de un proyecto de conservación y puesta en valor, es necesario efectuar un estudio contextual, y no sólo porque así lo exija la administración. La cultura material en contexto funerario multiplica las posibilidades de interpretación, en sus dos categorías principales: ajuares, como objetos que están en relación directa con el difunto, y ofrendas y otros elementos rituales que lo acompañan. No por ello se ha de establecer una lectura que equipare los objetos a una categoría estanca (estatus, género, etnia, etc.). Es por ello que las imperantes críticas posmodernas ponen el punto de mira en que los objetos no representan estatus socioculturales, y que a través de ellos no es posible establecer un rango, o mucho menos una identidad, sino que hay que tener en cuenta otros factores como la ideología o las acciones individuales, la "agency" o iniciativa (que no agencia). Los ajuares y otros objetos funerarios informan de las relaciones sociales, mostrando la complejidad de los vínculos entre ideología, acciones particulares y cultura material. Pero presentar como resultado de un estudio que la realidad es compleja o relativa, en nuestra opinión, no es una conclusión válida para un trabajo histórico-arqueológico. Quizás el historiador deba exigirse más, aun siendo en todo momento consciente de esa complejidad y de lo efímero —o relativo — de su propuesta. Hasta cuando sea superada por ulteriores investigaciones, esa propuesta será cimiento de futuros planteamientos.

Por otro lado, las deposiciones intencionadas en las tumbas de determinados objetos, como la cerámi-

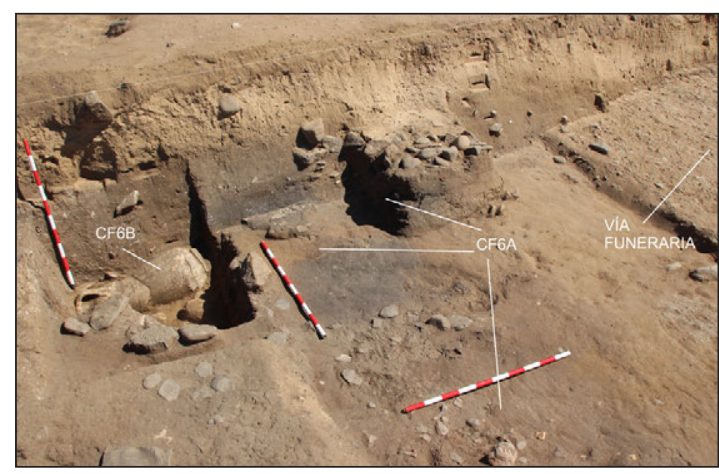

Figura 3. Conjunto funerario $6 \mathrm{~A}\left(1^{\circ} \frac{1}{2} / 2\right.$ siglo I) cortado por el $6 \mathrm{~B}$ (mm. siglo III). Campaña de 2014. ca (Fig. 3), y la asociación entre cada uno de ellos, serán clave para analizar los gestos funerarios (Denti 2013: 17). Esta "arqueología de los gestos" (ritual), será absolutamente dependiente de la "arqueología de los objetos" (contextual). La clave de la realización del estudio de una necrópolis será calibrar entre una "arqueología de la presencia" (en cuanto al elemento tangible, o sea, el objeto) y una "arqueología de la ausencia" (en cuanto a los gestos, las acciones o los individuos). Por ello es evidente que sólo con una cuidadosa y detallada excavación podremos estudiar algo que no vemos, pero que los objetos nos pueden ayudar a ver.

El contexto cultural en el caso que nos ocupa será primordial, debido a cuestiones tan básicas como que en el pensamiento romano encuentran difícil acomodo manifestaciones religiosas destinadas a asegurar la inmortalidad del alma (Scheid 1998). El peso de la tradición local, por lo tanto, será clave para comprender los procesos y restituir las actitudes ante la muerte, y ello es evidente en el caso de Baelo. Hasta mediados del s. I, un alto porcentaje de los sepulcros evidencian la esperanza en una vida de ultratumba, para la que se instalan elementos de protección del alma. Junto a estos aparecen otros que, según la norma religiosa romana (Toynbee 1971: 133), cuidan de los restos "físicos" y no tanto espirituales del difunto en el sepulcro, que se convierte desde la deposición en su nuevo hogar.

La lectura en contexto estratigráfico de estos objetos y su cotejo con otros espacios funerarios, en su contexto cultural, nos han llevado a enmarcarlos dentro del ámbito de lo neopúnico (Prados 2011; Prados y Jiménez 2015: 199), que no es sino una etiqueta cultural, artificial y tomada de la filología, pero que se corresponde con un determinado tejido socio-histórico propio del ámbito del estrecho de Gibraltar y de la baja Andalucía, que pone el acento en la importancia del legado fenicio-púnico y su perduración en época romana (Bendala 2002 y 2012; Mora y Cruz 2012). Igualmente, el complejo universo de las prácticas privadas o la etnicidad dificultarán sobremanera llegar a cualquier tipo de conclusión general, aunque la norma religiosa pueda ser común en las ciudades (Scheid 2005: 208). De ahí la importancia de observar cada detalle y ponderar cada una de las evidencias, buscando el equilibrio entre la tradición local y la innovación, entendida en el marco de los procesos de emulación o mímesis de una sociedad como la baelonense, que tan rápidamente quiso vivir "a la romana". Ya hemos aludido a la dificultad que acarrea tratar de conectar la identidad social y la cultura material (arqueológica), un ejercicio teórico en opinión de algunos (Morris 1992). Para determinados 
investigadores la cultura material no puede reflejar la identidad, que es una atribución individual cuya lectura tratamos de realizar desde el presente, con las dificultades que conlleva (Lowenthal 1985: 52; van Dommelen 2014: 45). Evidentemente, el ritual funerario puede presentar una imagen idealizada o una construcción de una meta no alcanzada en la vida, así como reflejar una identidad deseada. Aun teniendo en cuenta estas premisas, el estudio de la muerte en su contexto supondrá siempre un punto de partida (Fowler 2013: 523) y ofrecerá información de enorme relevancia sobre la identidad, tanto como el propio ritual, que aun sabiendo que no es estático, tampoco es espontáneo, y mucho menos improvisado (Rappaport 1999, 32).

La documentación textual romana nos habla de la importancia del rito funerario en el marco de las relaciones sociales y la comunidad. Exposición del cadáver, cortejo fúnebre, laudatio y erección de los monumentos funerarios quedan bien reflejados en la literatura romana (Toynbee 1971; Scheid 2005: 164), pero apenas sabemos nada de las manifestaciones privadas o de ciertos actos colectivos como los banquetes, y menos aún de otros elementos propios de esta necrópolis como por ejemplo el papel real de los célebres "muñecos", las llamativas tallas antropomorfas que tanta literatura científica han generado (Remesal 1979; Jiménez 2007 y 2008; Vaquerizo 2008 y 2010; Prados 2011, etc.) y que acompañan los sepulcros en Baelo.

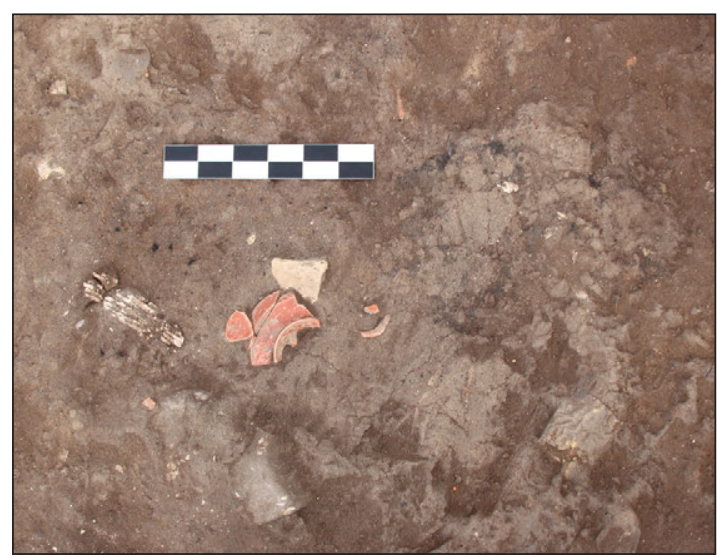

Figura 4. Detalle del banquete funerario del conjunto funerario 6A. Se observan los restos de túnidos y los fragmentos de copas y platos de TSG.

El estudio del contexto arqueológico sí que puede dar respuesta a algunos interrogantes atávicos, y aportar luz sobre aspectos concretos tales como los ritos de tratamiento y eliminación del cuerpo, las deposiciones funerarias en un nuevo espacio que deberá ser definitivo, y la elección/discriminación de determinadas categorías de objetos como parte del ajuar. Igualmente los restos de un peculiar y frugal banquete funerario excavado en 2014 (Fig. 4), pueden arrojar información sobre la instalación de este rito en Baelo en fechas tempranas del s. I, además de reflejar el consumo de atún en ambiente funerario por parte de la elite urbana. También la propia estructura de la necrópolis, el paisaje funerario generado a partir de la organización de los sepulcros en las distintas fases, bien especificadas a partir de la estratigrafía, aporta información sobre la concepción de la muerte y la necesidad de reservar un espacio óptimo para ella. Nuevas informaciones relativas al "objeto biológico", y por tanto menos simbólicas, están por venir con el avance de la investigación en los próximos años, a la espera de los resultados de las analíticas en curso: demografía, polimorfismo genético, dieta, patologías, etc.

\section{CIUDAD Y CIUDADANOS. EL ESTUDIO DE LA NECRÓPOLIS COMO REFLEJO DE UNA SOCIEDAD CAMBIANTE}

Sabemos de la potencialidad del análisis de la "dimensión social" que se puede desarrollar a partir del estudio de las prácticas funerarias (Saxe 1970; Binford 1971; Morris 1992), si bien siendo siempre conscientes de la ambigüedad inherente a las mismas, dado que cualquier tipo de "lectura social" es necesariamente subjetiva y sujeta por tanto a múltiples factores (Chapman 2013). Toda aproximación a la lectura social de los espacios funerarios va a depender, en concreto, de tres aspectos principales que podemos sintetizar: la realidad económica y social, la ideología religiosa y el peso de las tradiciones (Blaizot 2009a: 313). En este sentido, nuestra aproximación al mundo funerario romano ha de liberarse de nuestra percepción actual de la muerte y el hecho funerario, marcado por la invisibilidad y la pulcritud que contemplan la muerte como un trámite rápido, aséptico, y separado de la vida cotidiana. Hoy los camposantos se sitúan lo más apartado posible de los centros urbanos y tras muros lo suficientemente altos como para ocultarlos totalmente.

Nada más alejado de la percepción de la muerte por los romanos, que la entendieron como algo habitual y cotidiano, parte natural de la vida tanto como el propio nacimiento. Por ese motivo las necrópolis no sólo no se escondían de la mirada de los vivos, sino que eran elementos protagonistas a las entradas de las ciudades. Eran además lugares visitados no 
sólo el día del enterramiento, sino frecuentados con posterioridad para la realización de distintos ritos en honor del difunto.

Sabemos bien que la mentalidad humana lleva implícita la idea de que el momento de la muerte es tan sólo un paso hacia una segunda vida, generalmente mejor que la primera. Pero junto a las creencias en la trascendencia en el más allá, la muerte es el reflejo de otras muchas cosas: conductas, ideología, religión, superstición, etc. Advierte D. Vaquerizo sobre el especial cuidado que se ha de tener a la hora de pasar a interpretar los mensajes que emanan desde las manifestaciones públicas y privadas de la muerte. La muerte es el escenario ideal para la autorrepresentación, espejo de la familia o del grupo social al que pertenece el difunto (Vaquerizo 2010: 13) y por ello se ha de tener presente que el registro que localizamos en las excavaciones es claramente intencionado, emplazado con diversas motivaciones no siempre ligadas únicamente al acto funerario. No es preciso señalar que el difunto no elige en última instancia qué tipo de funeral, de sepulcro o de rito desea para sí...

Pero no sólo eso, la muerte en su realidad material que es la necrópolis, es reflejo y síntesis también de la comunidad urbana a la que pertenece, como receptáculo de memoria y "carta de presentación" de la misma orgullosamente expuesta ante la entrada (Zanker 2000). En el caso de la ciudad portuaria de Baelo, pues, tiene sentido que encontremos una necrópolis donde mar y puerto sean elementos principales, como veremos.

La ubicación de las necrópolis romanas es por tanto coherente con el carácter urbano de dicha cultura, caracterizada por la separación de los espacios con diferente funcionalidad. Aunque todo es ciudad, la urbe de los vivos y la urbe de los muertos, a su alrededor, están convenientemente separadas. En primer lugar, por la muralla, espacio simbólico que encarna el pomerium trazado por Rómulo, que rodea y limita el espacio de hábitat, y donde estaba prohibido enterrar a los muertos según la Ley de las XII tablas, que se quebrantó sólo en contadas ocasiones (Rascón y García 2011; Ruiz Bueno 2013). Pero en el caso de Baelo, las necrópolis estaban separadas de la urbe además por dos cursos de agua: el arroyo de las Villas en el caso de la necrópolis occidental y la chorrera Jiménez en el caso de la oriental; esta última pudo incluso haber estado rodeada de agua por sus cuatro lados a modo de una isola sacra (Prados 2015a, 96). Creemos interesante señalar que el elemento acuático, ya sea el mar, como los pequeños arroyos, las marismas o la laguna litoral que avecinaron la necrópolis (Alonso et alii 2007), desempeñaron un papel desde el punto de vista simbólico como purificador del espacio funerario, algo que hunde sus raíces en la tradición fenicio-púnica de la zona (Prados et alii 2011).

Las necrópolis formaron parte, pues, de la ciudad que rebosaba los límites de la muralla, de ese espacio periurbano que no podemos entender de forma separada a la ciudad y que constituye, de hecho, un fiel reflejo de sus dinámicas sociales e históricas (Goodman 2007: 2 y ss.). Las periferias urbanas albergaron también edificios de espectáculos, residencias aristocráticas, huertos y jardines, e infraestructuras diversas, pero nos interesa subrayar cómo sólo las necrópolis fueron exclusivas de estos espacios y, por tanto, parte esencial de los mismos (Fernández Vega 1994).

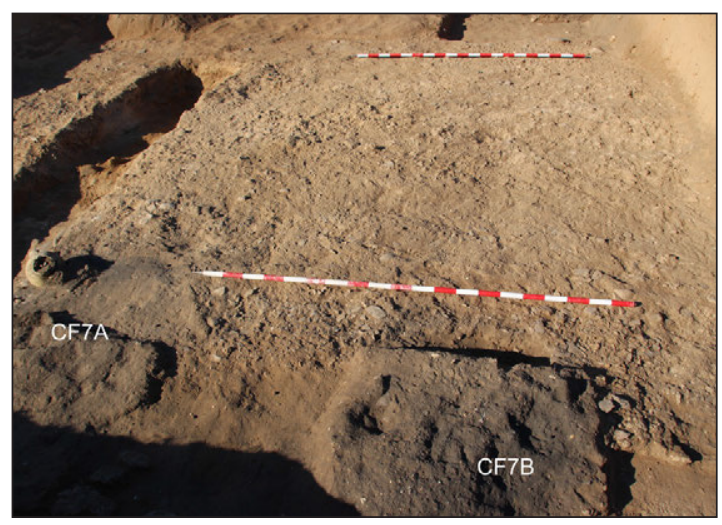

Figura 5. Dos cremaciones (ff. del siglo I-pp. del II) amortizan parcialmente el borde meridional de la vía sepulcral.

En Baelo, según apuntan nuestras excavaciones, la necrópolis está restringida a los muertos y el único reducto que puede ser usado por los vivos, que es la vía sepulcral construida a mediados del s. I, fue en pocas décadas ocupada parcialmente por sepulcros (Fig. 5), al menos en sus márgenes, lo que evidencia por un lado la gran densidad de enterramientos de la necrópolis y por otro, como consecuencia de lo primero, la exclusividad del uso funerario en este espacio. Ya en el s. IV tenemos algunos monumentos funerarios de cierta entidad que irrumpen y amortizan la vía claramente, como la gran tumba de inhumación con mesa de ofrendas adosada que apareció junto a un acotado altoimperial (Fig. 6). Nos parece claro, por tanto, que en Baelo la ciudad crece con su necrópolis, con una clara delimitación de los distintos usos del suelo (Prados 2015a).

Aunque algunos enterramientos con el tiempo sí que ocuparán otros espacios de la ciudad, como el teatro, las termas occidentales o las áreas próximas a la muralla (García 2015: 105 y fig. 8), la documentación arqueológica que manejamos hasta el momento 

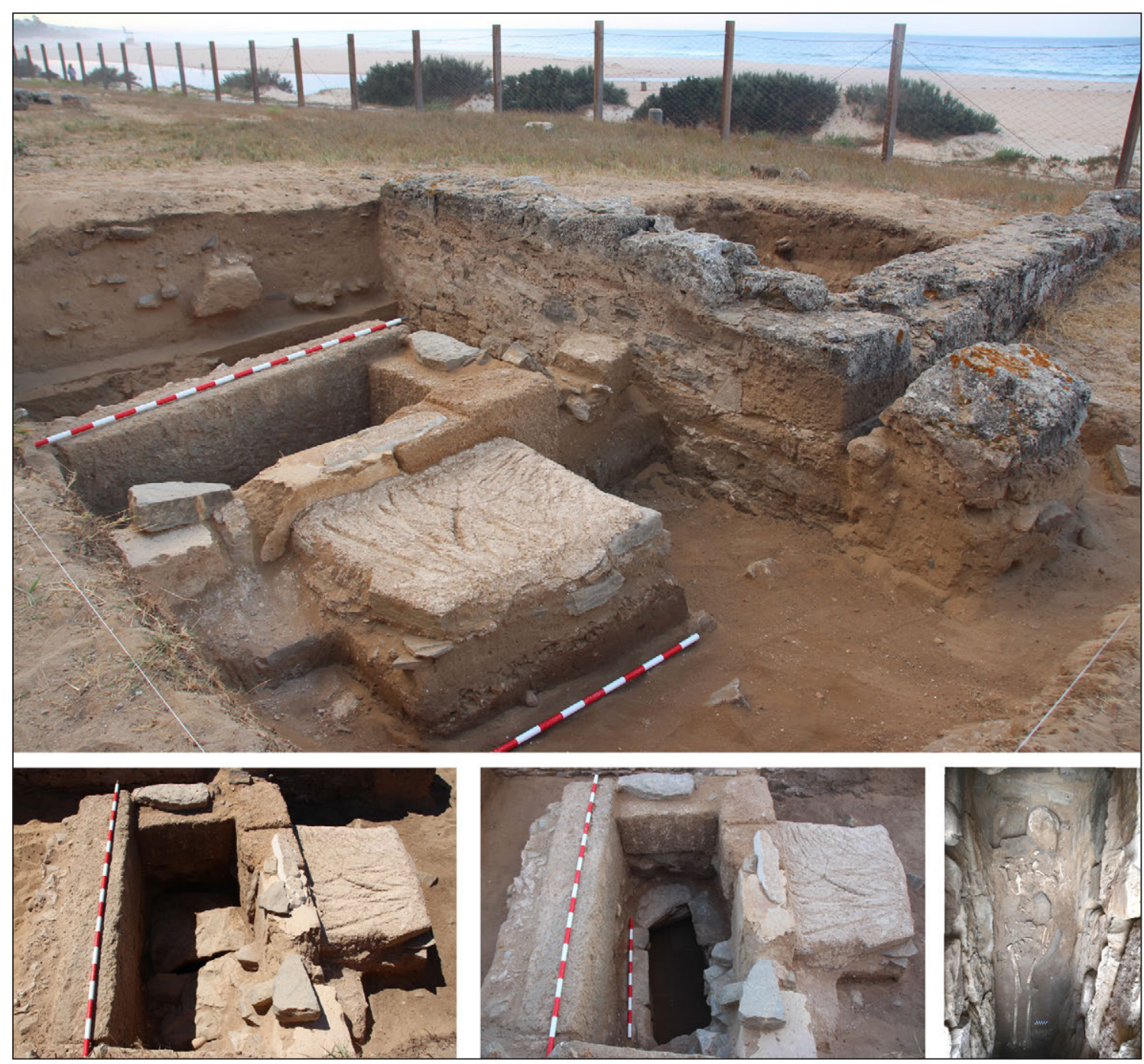

Figura 6. Imágenes de la excavación del mausoleo tardorromano equipado con mesa de ofrendas (siglo Iv) que amortiza la vía funeraria en este sector. Obsérvese que se adosa a un acotado altoimperial.

indica que aparentemente la función funeraria de esta necrópolis nunca fue sustituida por otra actividad, pues todo apunta a que ya en época antigua se abandonó siendo aún espacio funerario, y los materiales que aluden a otros usos son muy posteriores. Al respecto incluso cabe señalar nuevos usos funerarios del espacio en época medieval tras un hiato de varios siglos (Prados 2015a).

No encontramos por tanto, como en otras ciudades, una usurpación de áreas de la necrópolis por otros usos, como los industriales, lo que a nuestro parecer se debe a lo arraigado de la cultura urbana, una continuidad en el uso de los espacios, un respeto hacia los lugares sagrados, y al hecho de estar la necrópolis bien delimitada por cursos de agua. Seguramente también a que Baelo no debió tener la densidad poblacional de otras ciudades. Pero también hubo de influir el hecho de que las industrias salazoneras estuviesen dentro de la ciudad, un rasgo que es característico, aunque no el único, de las ciudades romanas del Círculo del Estrecho (Bernal 2006), lo que dejaba más espacio liberado en el entorno periurbano. De todas formas, tal y como ha puesto de manifiesto el reciente descubrimiento de unas termas suburbanas, es aún mucho lo que nos queda por conocer del territorio periurbano de Baelo (Bernal et alii 2013).

La información arqueológica que manejamos apunta a que la de Baelo es una auténtica ciudad de los muertos, creada a tal efecto, siguiendo ese concepto de Estrabón (Geo. XVII) que en la bibliografía más 
reciente ha ido quedando relegado al más generalizado de "espacio funerario" (Vaquerizo 2002; Blaizot 2009 b). En otros lugares, sin el hondo arraigo del concepto de lo urbano y sin la planificación que refleja la necrópolis oriental, las necrópolis se instalan en espacios periurbanos, muchas veces inicialmente como sepulturas aisladas que generan en su entorno pequeños grupos de tumbas menores.

Un tema que ha llamado la atención tradicionalmente en Baelo es la escasez de viviendas, de espacios dedicados a lo doméstico, cuando por lo demás cumple a la perfección los rasgos de una ciudad romana en cuanto a organización urbana y monumentalidad. Esto nos remite a la doble naturaleza de la ciudad, la urbe como materialización de la civilitas y escenario de la vida pública, y el territorio productivo como caras de una misma moneda. La clave está sin duda, por tanto, en el territorio y en el espacio periurbano, donde, como ya señaló M. Ponsich (1988: 96 y ss.), estarían las cabañas donde habitarían los pescadores que irían itinerando de una orilla del Estrecho a otra en función de la temporada del atún. Cobra interés la consideración jurídica del litus, el espacio de tierra bañado por el mar, un espacio inestable entre este, que era dominio público, y la tierra que puede estar sujeta a propiedad, y cuya única excepción de ocupación fueron precisamente las cabañas de pescadores (Alemán 2013; Masi 2014). Así consta en el Digesto de Justiniano: In mare piscantibus liberum est casam in litore ponere, in quam se recipiant, "los pescadores tienen derecho a establecer su casa en la orilla del mar para guarecerse" (D 1.8.5.1. Gai., 2 rer. cott.).

Además de la ubicación y la relación de la necrópolis con la ciudad y otros elementos periurbanos, es necesario tener en cuenta otros significados como por ejemplo su carácter simbólico. A pesar de la importancia para el conocimiento de la mentalidad romana de aspectos como la visibilidad o la percepción del espacio, estos han sido apenas abordados por la investigación dedicada al mundo funerario romano, con el añadido de que contamos con textos que, al contrario que para otras épocas, nos asisten en este tipo de estudios (Pearce 2011). Ello abre una línea de investigación apenas explorada que aportará una gran riqueza a nuestra visión de la religiosidad romana, al tener en cuenta el papel de los monumentos funerarios en el paisaje, su relación con otras actividades y espacios, así como su relación, visual o espacial, con elementos que les confieren prestigio (Mischka 2012).

Estos aspectos resultan especialmente interesantes en el caso de las ciudades portuarias y las necrópolis costeras, al entrar en juego la visibilidad del camposanto desde el mar. En Baelo, tanto la necrópolis oriental como la occidental serían visibles, no sólo por los viandantes que se aproximaran a la ciudad por las rutas terrestres, sino también por las embarcaciones que se aproximaran a su puerto. Se trata, por tanto, de verdaderas necrópolis portuarias, según un patrón que parece repetirse en otras ciudades del Estrecho como Gades, Carteia o Tingi (Jiménez Vialás 2015). Además, la cercanía no sólo del mar sino de zonas pantanosas, "espacios intermedios" como marismas o lagunas litorales, tiene un carácter evocador de tránsito entre la vida y la muerte, que concuerda perfectamente con el simbolismo funerario del viaje (Ruiz-Gálvez 1995: 25), lo que enlaza a su vez con el Estrecho como confín del mundo conocido o camino al más allá, atributos de los que quedaría recuerdo aún en época romana (Blánquez et alii 2012).

\section{LA MATERIALIDAD DE LA MUERTE EN BAELO. ANÁLISIS DE LAS PRÁCTICAS FU- NERARIAS}

Denominamos prácticas funerarias a todos aquellos actos que se realizan en la necrópolis y que se caracterizan por la voluntariedad de su ejecución, generando por ello unas evidencias materiales óptimas para reconstruir las distintas actitudes humanas ante la muerte. Las prácticas funerarias son las responsables de dejar un registro arqueológico intencional, afectado solamente por procesos tafonómicos, en contraposición al que se puede localizar en otros yacimientos, donde este será involuntario, sometido a los cambios derivados de los procesos postdeposicionales.

El carácter repetitivo de muchos de estos actos nos permite reconocer un conjunto de gestos y de ritos funerarios coherentes, al tiempo que nos ayudan a estudiar los cambios, la incorporación de nuevas creencias y su evolución. En paralelo, analizar esos cambios nos facilita observar el conservadurismo de algunas de las prácticas, su perduración a través de los años y apreciar su vínculo con determinadas identidades o grupos. Una de las primeras prácticas a analizar será el tratamiento de los restos del difunto.

Para el periodo objeto de estudio y en el sector de la necrópolis que hemos excavado, hay que señalar la elección prácticamente exclusiva de la cremación como ritual de eliminación del cuerpo. En la necrópolis oriental las inhumaciones comienzan a aparecer a partir del s. III d. C. (Fig. 7), y así se constata tanto en las excavaciones antiguas como en las desarrolladas actualmente (Prados 2015b: 109).

El protagonismo del personaje enterrado se ponía de manifiesto a través de los objetos depositados en el interior de la cámara (ajuar), y su rol social se 


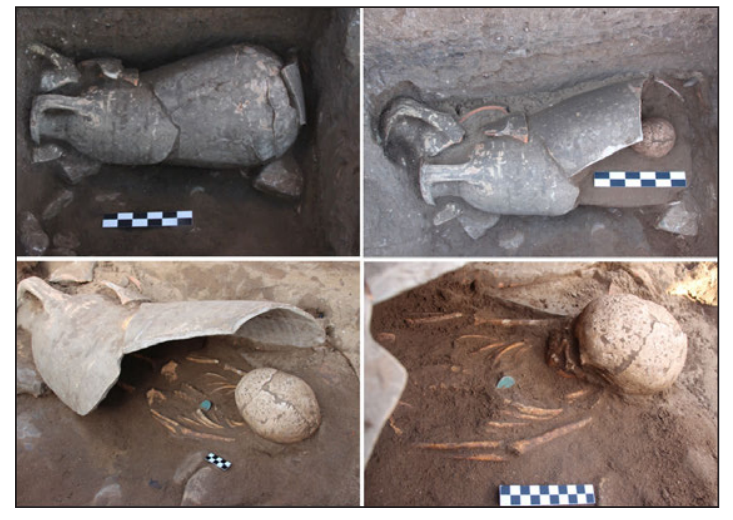

Figura 7. Proceso de excavación del conjunto funerario 6B. Se trata de una inhumación infantil en ánfora salazonera tipo "Puerto Real 2" (siglo III).

podía reflejar en los elementos que se colocaron fuera (ofrendas y otros indicios del ritual) y que provenían de unas celebraciones colectivas que, como se ha dicho, suponían la auto-afirmación de un determinado grupo. En esta misma línea habría que observar el monumento funerario, donde además se podrían medir otras cuestiones vinculadas con el estatus o la riqueza.

\subsection{Dentro De la tumba}

Las cremaciones que se han excavado son depósitos secundarios, ya que todas están ubicadas en un lugar diferente al ustrinum. En cualquier caso, las cremaciones aparecen guardadas en urnas de piedra de diferente tipología, en vasos de cerámica y, en algún caso, directamente sobre el suelo dentro de fosas previamente habilitadas para ello, a veces con algunas lajas de piedra colocadas como base. La escasez de huesos en los depósitos es indicativa, además, de un proceso de selección desarrollado directamente sobre la pira, por lo que la presencia del difunto en la tumba fue claramente simbólica, propia de una sinécdoque ritual (Tarlow 2013). Esta recogida de hueso, por lo que hemos ido viendo, es una pequeña parte del total si se compara con la masa teórica experimental expuesta en diversos estudios de referencia (Herrmann 1976; MacKinley 1993).

Ninguno de los elementos contenedores tiene trazas de rubefacción, por lo que no estuvieron presentes directamente durante la combustión. Sí lo estuvieron otros objetos personales, como veremos a continuación. Estos datos nos hacen plantearnos la existencia

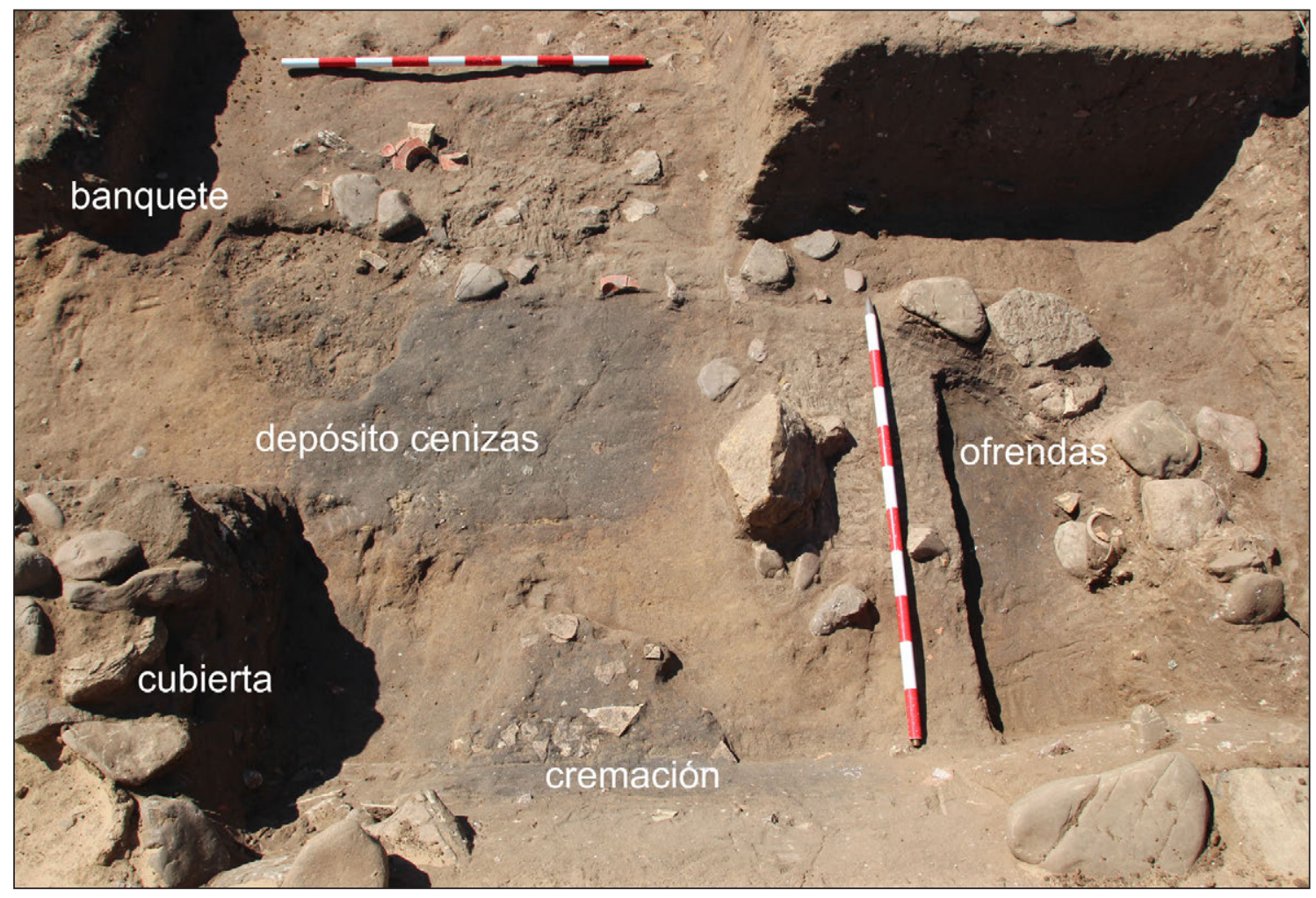

Figura 8. Conjunto funerario 6A. Se observan las distintas partes que lo componen, restos de la cubierta, enterramiento, espacio para ofrendas, depósito para las cenizas y área de banquete ritual. 
de un espacio de cremación colectivo, aún por localizar, sobre todo porque en todas las excavaciones realizadas hasta la fecha en esta necrópolis no se ha documentado con total seguridad un ustrinum como tal. Incluso dudamos sobre que la cámara que contiene cenizas en los característicos recintos dobles de Baelo lo sea, aunque tantas veces se haya repetido esta identificación (Remesal 1979; Jiménez 2008; Prados et alii 2014).

Estas cámaras, que aparecen al norte o al sur pero siempre en la parte más alejada de la vía sepulcral, no presentan trazas de combustión. Sí es cierto que contienen cenizas, como es el caso de la llamada "tumba de las guirnaldas" excavada por Bonsor y recuperada en 2010, si bien las paredes no presentan resto alguno de la combustión. La excavación de un sepulcro complejo en 2014 (CF6) compuesto de diversas áreas (Fig. 8), entre las que destaca una zona abierta para la celebración de un banquete fúnebre y un espacio cuadrangular excavado en el suelo, delimitado por una pequeña capa de tierra amarilla y relleno únicamente de cenizas (Fig. 9, imagen 7), nos hace plantear si estos espacios de los recintos dobles pudieron funcionar como depósito de cenizas provenientes de la cremación trasladados al mausoleo junto a los contenedores funerarios.

En las tumbas más sencillas y que se corresponden con la fase más antigua (que fechamos hasta mediados del s. I) las urnas de piedra guardan los huesos más grandes, así como los fragmentos del cráneo y las mandíbulas. Los huesos más afectados por la combustión aparecen a veces localizados en el mismo sedimento que cubre las urnas. En todos los casos dentro de los contendedores aparecen tanto huesos como cenizas y carbones, algo diferente a lo que se observa en las cremaciones del vecino oppidum de la Silla del Papa, más próximas a los rituales protohistóricos y donde las urnas únicamente albergan huesos.

Dentro de las urnas se documentan algunos objetos que acompañaron al cadáver en el momento de la cremación (depósito primario) y otros que fueron incluidos después junto a los huesos (depósito secundario). Se trata de un dato interesante pues esos elementos seguramente eran empleados por el difunto en vida y no fueron necesariamente colocados después, como los otros que se recogen en buen estado sin traza alguna de termoalteración. Los objetos del depósito primario suelen ser estrictamente personales. Son des-

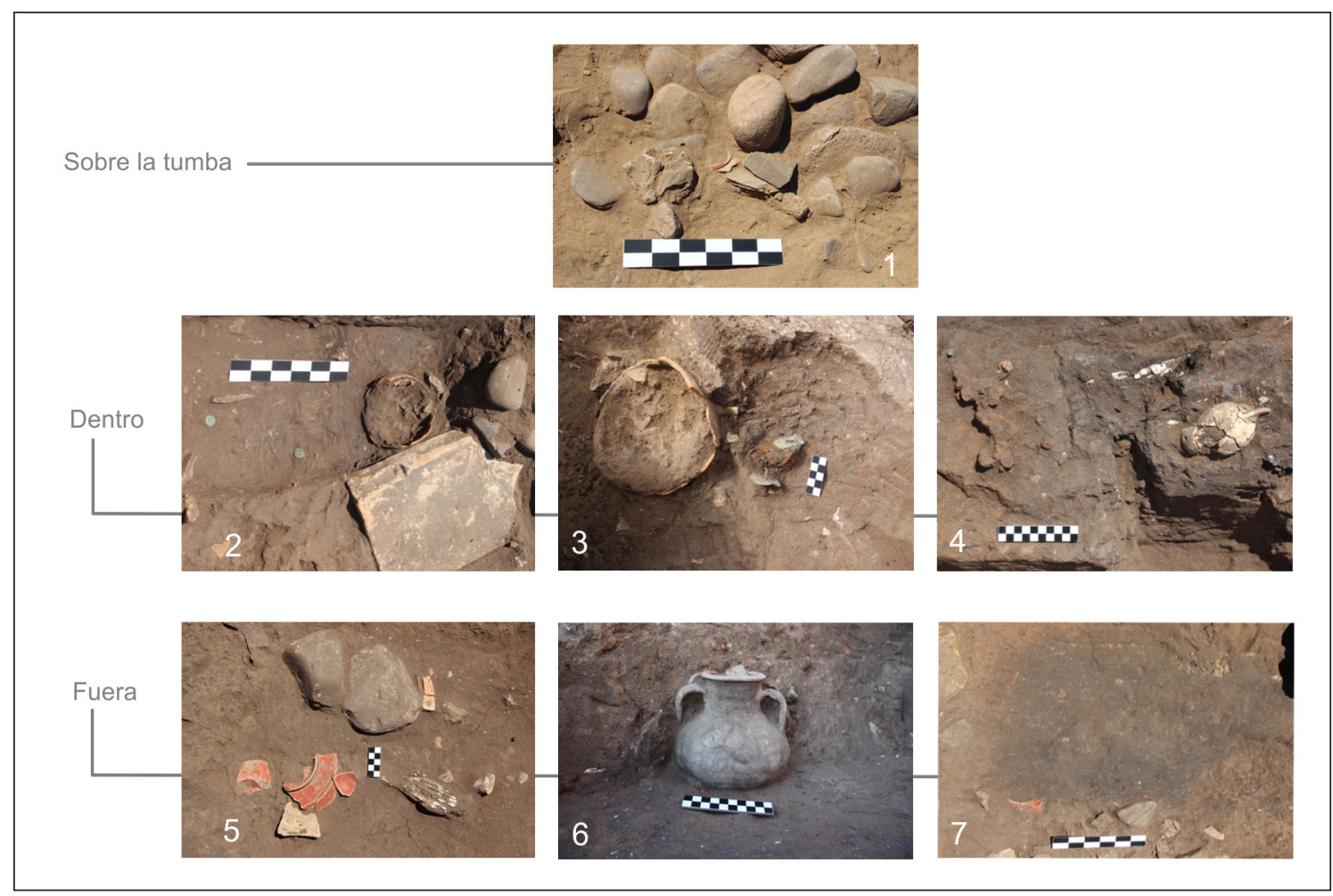

Figura 9. Conjunto funerario 6A. Elementos localizados sobre la tumba: 1, platos y copas de TS. Dentro de la tumba: 2 y 3 , urnas del ajuar, monedas y otros elementos metálicos, 4 lucerna colocada boca abajo sobre restos humanos cremados. Fuera de la tumba: 5 , restos de banquete, 6 ofrendas y 7 fosa con cenizas. 
tacables las cajas de sellos o porta-amuletos, como una de bronce localizada en 2012, que pudo albergar cabello del difunto, cera, o alguna sustancia aromática impregnando un tejido, y de la que conocemos paralelos en necrópolis de ambientes púnicos como las de Ibiza (Alfaro 2007: 41). También son frecuentes los collares con cuentas de pasta vítrea, de distintos tipos y colores, y de un acentuado gusto punicizante, y algún otro objeto de adorno personal como colgantes o pendientes de oro, como el exhumado en 2014. De los objetos que se depositaron después, dentro de las urnas, destacan por ejemplo los objetos de tocador (pinzas, agujas, acus crinalis de hueso o espejos de bronce) y de adorno personal como pulseras o fíbulas.

Algunos de los objetos se podrían atribuir a un determinado género, a pesar de los problemas que ello plantea debido a la dificultad de cotejarlos con los restos biológicos cremados. Sí consideramos llamativo que los elementos del ajuar a los que se les puede atribuir un perfil femenino están mayoritariamente incluidos dentro de urnas de piedra, como si se reservase este contenedor para cremaciones femeninas. Como los aspectos relacionados con las identidades, la cuestión del género tiene un enorme interés en esta necrópolis y está por desarrollar. Como la etnicidad, no sólo se expresa en un tipo de tumba o en un epitafio, sino también en los objetos de uso cotidiano y en los que se relacionan con el vestido (Carroll 2013: 573), es por ello que su detallado estudio, en paralelo al futuro análisis de los restos óseos, habrá de ser clave para ampliar información.

En lo que concierne al material cerámico, existe para las deposiciones del s. I un ajuar tipo. Aunque es complicado reducir la descripción por razón de espacio, hay que aludir a la especial variabilidad que se observa. El dato quizás más relevante es la discriminación del uso de terra sigillata en el interior del sepulcro (que en cambio aparecerá con cierta profusión al exterior, formando parte de rituales postdeposicionales). Para época Julio-Claudia e inicios de la dinastía Flavia el esquema de ajuar más frecuente lo compone la caja de piedra o la urna cerámica como contenedor de cenizas. Normalmente son formas globulares sin asas o jarras monoansadas que podían contener en su interior, además, un vaso de paredes finas o vidrio. Los contenedores cerámicos aparecen cubiertos por un cuenco de cerámica común, y pueden estar acompañados por ungüentarios de cerámica o vidrio, además de diversos objetos metálicos como clavos y otros vasos cerámicos a modo de ofrenda.

Se ha documentado la deposición de lucernas pero con una peculiar disposición: en el sepulcro complejo (C-6) excavado en 2014, con los huesos recogidos en una pequeña fosa, una lucerna apareció boca abajo directamente sobre ellos (fig. 9). En el sepulcro circular (C-5) de la misma campaña otra lucerna boca abajo cubre los huesos; otras veces las lucernas se ubican fuera de la tumba, sin contacto con los huesos, y en su posición normal, como si se tratase de una ofrenda posterior. La posición de la lucerna evidencia un gesto funerario y debemos encontrar una respuesta. En contextos galorromanos la ubicación de la lucerna junto a los huesos o quemada con ellos es un rasgo arcaizante; parece que allí desde época de Augusto se generaliza el uso de las lucernas en los ajuares pero siempre como depósitos secundarios correspondientes a las ofrendas (Bel et alii 2009: 139). También en contextos africanos se vinculan con individuos infantiles y según la postura de la lucerna, el gesto podría tener dos lecturas: la oposición a las tinieblas de la muerte, si está en su posición original, lista para iluminar al difunto en el más allá, o más bien lo contrario, sin función alguna y sólo para simbolizar el carácter irremediable de la muerte (De Larminat 2012: 309) si está boca abajo y por tanto inutilizada.

En otras necrópolis también se han conseguido aislar los materiales cerámicos que acompañaron al difunto en la pira funeraria, como en Porta Nocera (Pompeya), donde aparecen piezas que contuvieron perfumes o alimento (Tuffreau-Libre 2013: 171). Estas piezas que, como en Baelo, se colocaron después dentro de los sepulcros, muestran signos evidentes de alteración térmica, y muchos de ellos presentan impactos propios de fracturas voluntarias, indicio de un evidente gesto de amortización ritual (TuffreauLibre 2013: 173) que también observamos en nuestro caso de análisis.

\subsection{Fuera DE LA TUMBA}

De los elementos que encontramos junto a la tumba, pero en el exterior, como parte del depósito secundario, destacan en primer lugar las monedas. El conjunto de monedas recogido en contexto arqueológico es muy significativo, aunque no es demasiado abundante. Las piezas aparecen siempre fuera del contenedor a excepción de un denario de Tiberio hallado dentro de una caja de piedra (Remesal 1979: 31, tumba XX). Además, aparece una única moneda por conjunto funerario y no por sepulcro, es decir, por grupo o familia y no por individuo, como cabría esperar. Esta es la razón que esgrimimos para plantear que no se trata de óbolos para el pago ritual al barquero Caronte, tan clásico de la tradición grecorromana. En Baelo los conjuntos funerarios se componen normalmente de varios enterramientos (Remesal 1979: 19; 
Prados et alii 2012). La ubicación de estas monedas tendría un valor de protección o profilaxis, en una línea similar a la que ha sido señalada para algunas tumbas de la necrópolis de Cádiz y que se vincula con la perduración de la religión púnica (Arévalo 2010: 517).

Tampoco parece casualidad que haya una especial predilección por el uso de monedas antiguas, casi reliquias, como amuletos, y que éstas presenten con frecuencia en sus tipos una iconografía vinculada con el dios Melkart. Son monedas procedentes de cecas diversas y que podrían reflejar un culto específico dentro de este ambiente funerario ligado a una divinidad masculina de tradición púnica. Un ejemplo es el uso de una moneda acuñada en Carmo a finales del s. II a. C. que presenta una cabeza de Melkart a la izquierda en el anverso. La inhumación infantil en ánfora (tipo Puerto Real 2) excavada en 2014 (fig. 7), fechada en un claro contexto del s. III d. C., presentaba sobre el pecho, y no en la boca, un as de Claudio acuñado en Roma hacia el año 41. ¿Estaban aún en curso estas monedas? ¿Eran realmente amuletos?

Si únicamente hemos documentado una moneda por conjunto funerario, en cambio, aparece un clavo de bronce retorcido junto a cada una de las deposiciones. Es muy posible que cada clavo fuese ubicado con la intención de "fijar" el alma del difunto a la tierra (Alfayé 2009: 190; Vaquerizo 2010: 41). La aparición de estos clavos se asocia a enterramientos de cremación como los aquí expuestos y a inhumaciones infantiles (Vaquerizo 2011: 219), relacionado pues con un rito específico para las muertes prematuras. No cabe otra función para ellos, debido a su posición muestra de un claro ejercicio intencionado. Se han localizado igualmente varias llaves, que como las monedas, aparecen emplazadas fuera de las deposiciones. El uso de llaves entre los objetos que se colocan fuera de la deposición puede ser leído desde distintos puntos de vista: se puede tratar de las llaves que abren las puertas del más allá o de las de la casa que habitarán los difuntos en su vida de ultratumba.

Las lecturas son múltiples, si bien el amplio volumen de información que se maneja permite profundizar en las mentalidades, y facilita la reconstrucción de las manifestaciones religiosas y el reconocimiento de las supersticiones. En cuanto al ritual, concretamente la ceremonia que se desarrolló durante el entierro, hay un aspecto importante que es preciso subrayar: no se encuentra terra sigillata, la clásica vajilla de mesa de la época, dentro de las deposiciones, quedando este espacio reservado para el vidrio y los vasos de paredes finas o la llamada "cáscara de huevo" (Remesal 1979: 45). Por el contrario sí es frecuente localizar fragmentos de sigillata dispersos sobre los niveles que cubren los enterramientos. Se trata de formas repetitivas de TSG (formas Drag. 35/36 y Drag. 24/25) usadas para beber y libar líquidos sobre los sepulcros, que una vez usados eran amortizadas, seguramente lanzadas y rotas contra las estelas.

\subsection{Sobre LA TUMBa}

A la hora de interpretar son tan importantes los objetos que están en relación directa con el objeto biológico, tanto dentro como fuera del sepulcro, como las prácticas funerarias que se documentan "sobre la tumba" es decir, por encima del nivel de "uso funerario", en lo que hemos llamado "nivel de circulación" (Prados et alii 2014) entendido este como de uso y frecuentación esporádica por parte de los vivos (Fig. 10). En este sentido uno de los grandes hallazgos que hemos realizado ha sido la localización de la vía funeraria principal que, saliendo de la puerta oriental de la ciudad, vertebra la necrópolis y proporciona una información de enorme relevancia sobre cómo se organizó el paisaje funerario. También lo son, en

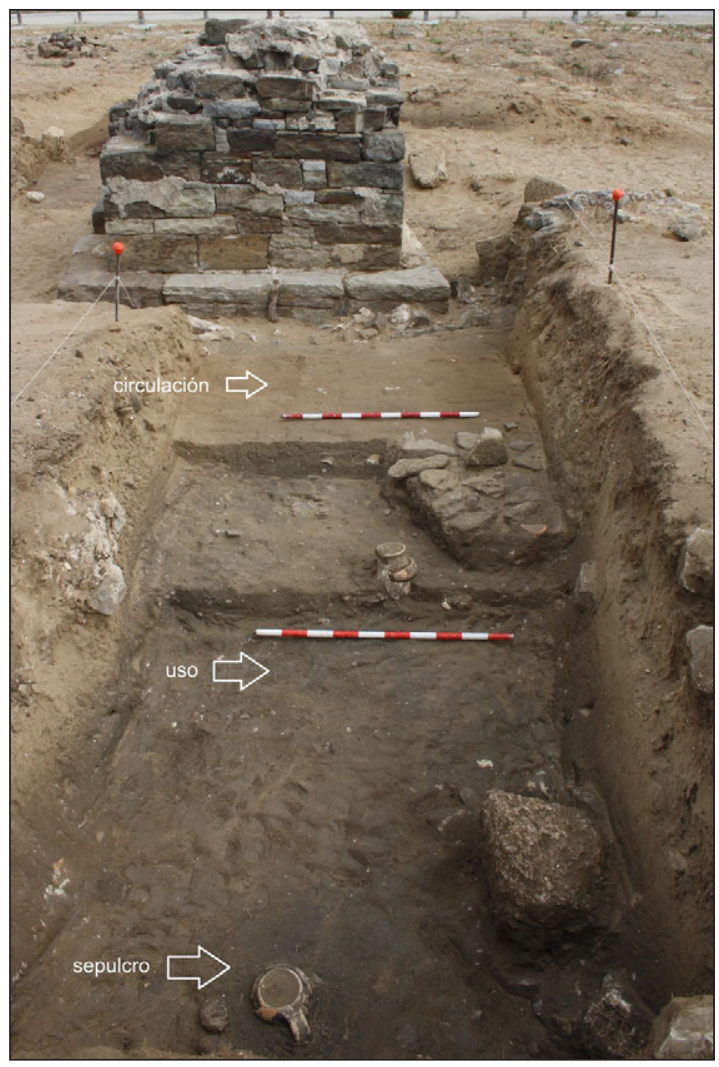

Figura 10. Niveles de enterramiento (uso funerario) y circulación de la necrópolis. 
una escala menor, los niveles de circulación que se localizan en torno a las sepulturas, a veces de una entidad que permite denominarlos como diverticula, siguiendo la nomenclatura clásica, y otras veces solamente pequeñas áreas, a veces incluso pavimentadas con cantos rodados, en las que se detectan numerosos elementos propios del ritual particular y colectivo.

Sobre la tumba será evidentemente el monumento funerario el elemento más significativo. Además de señalizadores de sepulcros, los monumentos son la plasmación de las experiencias colectivas, de la memoria acumulada y un reducto en el que se intentaron asegurar las perspectivas futuras a través de una arquitectura imperecedera. En algún caso baelonense se trata de superestructuras monumentales, que acentuaban el protagonismo y la preeminencia del grupo gentilicio, que entroncaba genealógicamente a través del memorial externo con un personaje significativo de la familia, algo que se vislumbra en la necrópolis de monumentos circulares de la Silla del Papa (Moret y Prados 2014). Como es lógico, los monumentos más prestigiosos ocuparían un lugar preeminente del espacio periurbano, como una evidente manifestación de ostentación. Dado que se conoce bien la tipología de monumentos funerarios de la necrópolis de Baelo (Paris et alii 1926; Remesal 1979; Prados 2015a) no nos detendremos en describir los tipos.

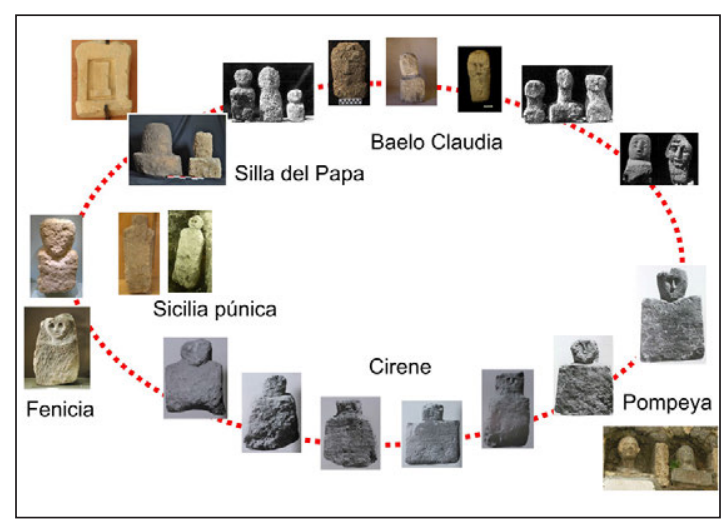

Figura 11. Propuesta evolutiva de las estelas de Baelo y de otros espacios funerarios afines en el mediterráneo centro-occidental.

Por el contrario, sí observaremos uno de los elementos más sencillos y a la vez más interesantes de la necrópolis: las estelas funerarias, a veces equiparadas a los célebres muñecos o genios funerarios tan característicos de esta necrópolis (Remesal 1979; Vaquerizo 2008; Jiménez 2007; Prados et alii 2014; Prados 2015b entre otros) y que no trataremos en esta ocasión aquí, o con "betilos" por su carácter anicónico (Seco 2010). Una vez más, su contexto ha de ser fundamental para tratar de atribuir una funcionalidad, más allá que lo que nos sugiera su soporte pétreo o su apariencia (Fig. 11). Se trata de estelas que marcan en la vertical la ubicación de sepulcros (Fig. 12) y que distan de estos entre $30 \mathrm{~cm}$ y $1 \mathrm{~m}$. Como cualquier monumento, son la plasmación física, por encima del sepulcro y en la misma escala que los vivos, del difunto enterrado. Pero también delimitan un sepulcro colectivo, por lo que no siempre han de leerse en el plano individual. A veces son de calcarenita, en forma de columna con una pequeña base, otras veces son cilíndricos y otras simplemente se trata de cantos rodados, con una de las caras planas que es sobre la que se apoya.

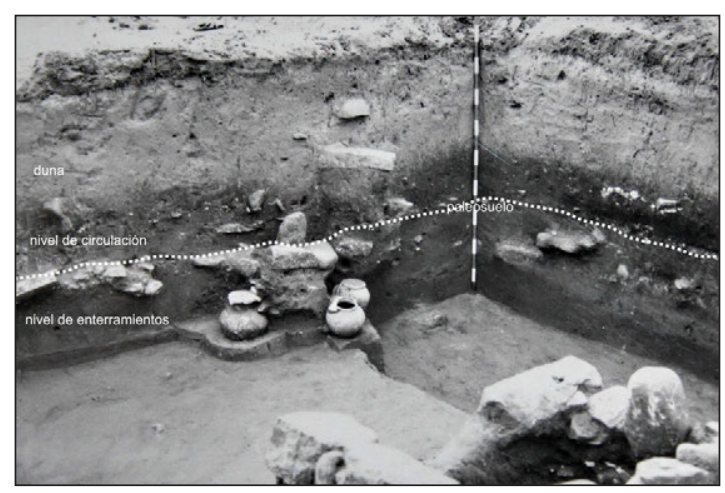

Figura 12. Campaña de 1973 (Archivo Casa de Velázquez). Se observan las estelas por encima del nivel de circulación señalando conjuntos funerarios.

La propia evolución de la necrópolis a lo largo del s. I conlleva que estas estelas vayan variando tanto su tamaño como su forma, apareciendo tipos complejos rematados en forma de frontón y acroteras. Con la necesidad de señalar nominalmente las sepulturas que conlleva la incorporación de la epigrafía sobre soporte pétreo en la necrópolis, hecho que fechamos en la segunda mitad del s. I, los tipos se multiplican y surgen otros señalizadores de tumbas como las arae funerarias o los podios.

En las estelas y en los espacios circundantes encontramos el registro de la celebración de diferentes ritos vinculados con la comensalidad. Sobre las estelas se rompen vasos cerámicos de paredes finas o de terra sigillata que habían sido empleados en banquetes funerarios o en ceremonias de libación. En torno a las estelas hemos recogido los fragmentos dispersos en un diámetro de entre 2 y $3 \mathrm{~m}$ de formas destinadas a la ingesta de líquidos que, seguramente, fueron amortizadas tras un único uso. Todos ellos muestran signos evidentes de destrucción voluntaria $\mathrm{y}$ fuertes impactos. 
Sobre la libación, hay que señalar que no se ha documentado ningún tipo de hueco habilitado para las profusiones, como tampoco existen estructuras para la celebración de banquetes que, como sucede en Tarraco (Ciurana 2011: 343) serían parcos y sobrios. Ya se ha apuntado que en la campaña de 2014 pudimos excavar los restos de un banquete ritual celebrado delante de un sepulcro evidenciando, entre otros elementos, el consumo de túnidos (Fig. 4). Junto a los vasos y platos de TSG rotos aparecieron numerosos elementos orgánicos de los que las vértebras y las aletas dorsales de los túnidos eran las más características. Si acaso, en los monumentos emplazados junto a la playa, que fechamos en el s. II d. C., alguna de las estructuras externas puede interpretarse como parte de triclinios o mensae. Se trata de tumbas más complejas y que apuntan a un rito distinto, más cercano a las costumbres itálicas, que conlleva la acogida de eventuales visitantes. Para los sepulcros de la primera fase, pues, no se constatan elementos arquitectónicos erigidos ex profeso para celebraciones o ritos colectivos.

Como otros elementos de profilaxis, cabe destacar la aparición de conchas colocadas en las cabeceras de algunas tumbas. La simbología de las conchas se relaciona con el renacimiento y la eternidad, en clara relación con el mundo de la muerte y el más allá. Aunque se ha relacionado con los cultos a Mitra y con el cristianismo en fases posteriores, nos parece de nuevo un elemento religioso que se suele asociar al ritual funerario fenicio-púnico y que tiene paralelos en las necrópolis de Cádiz (Niveau de Villedary 2004; Mesa y Niveau de Villedary 2014: 80). En el caso púnico, además, estos elementos aparecen vinculados a tumbas infantiles, como en el ejemplo ibicenco del Puig des Molins (Gómez Bellard y Gómez Bellard 1989: 224). Igualmente hemos localizado un útil de sílex negro junto a una de las estelas. Se trata de un acto llamativo porque es un objeto claramente exógeno que fue colocado voluntariamente sobre la tumba. El hecho de tratarse de un ejemplar único quizás le reste importancia, pero lo hemos querido citar porque este tipo de ofrenda se repite, de nuevo, en otras necrópolis costeras púnicas como las de Cádiz (Niveau de Villedary 2009: 171) o en la necrópolis romana excavada junto a la colonia fenicia de Toscanos (Arteaga 1988: 137).

De los elementos que se colocan sobre el sepulcro hemos de volver a mencionar los clavos, que adquieren gran protagonismo. Los ejemplares de Baelo aparecen hincados junto a las estelas y generalmente retorcidos. A pesar de que se han buscado diversas explicaciones para la aparición de clavos, generalmente relacionadas con cajas funerarias o con las estructuras y armazones de madera de las piras (Bel et alii 2009: 117) la explicación de la funcionalidad de los clavos de Baelo ha de ser similar a la vista en el párrafo anterior para otros elementos profilácticos. Cabe indicar sobre los clavos que detectamos una cierta evolución que arranca con el uso de algunos modelos de bronce, bastante estilizados en las primeras cremaciones, que se van sustituyendo por otros mucho más gruesos y de hierro en las más recientes.

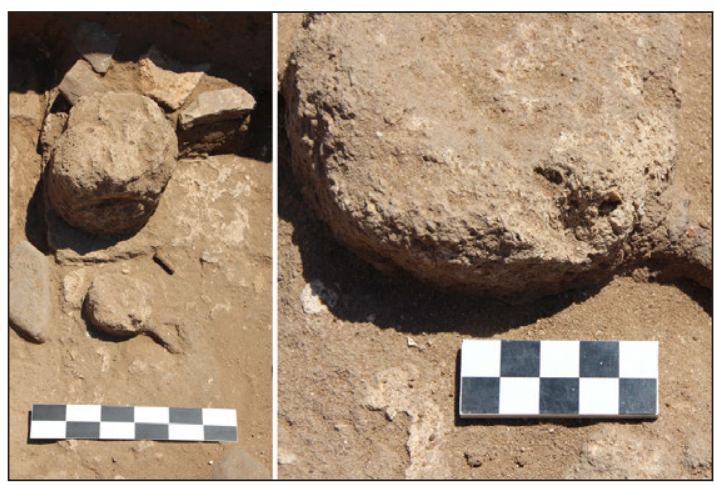

Figura 13. Detalle de dos estelas con sendos clavos hincados en contacto. Campaña de 2014.

En 2014 excavamos dos pequeñas estelas funerarias que iban acompañadas de sendos clavos (Fig. 13). Estos habían sido colocados, cuidadosamente, en paralelo al suelo y con la cabeza tocando el cuerpo de la estela. Su pertenencia a la estructura funeraria queda descartada, ya que fueron colocados sobre el enlucido de la estela. Es decir, fueron depositados directamente sobre la estela, una vez que esta había sido terminada. Lo que ya no podemos saber es si lo fueron en el momento del enterramiento o algo después, en una visita posterior a la tumba.

Queremos destacar lo frágil y efímero de este registro, dado que por encima de ese depósito tan sólo quedaba el nivel de abandono de la necrópolis. Quedó sellado, por tanto, ese ritual, que sin duda debió de estar presente en otras sepulturas de la necrópolis pero que dada esa aludida fragilidad no ha llegado hasta nosotros. De este modo podríamos explicar la abundancia de clavos descontextualizados en los niveles de circulación de la necrópolis. En cuanto a su definición, se trataba de un curioso ritual claramente postdeposicional, que puede tener diversas lecturas. Nuestra propuesta - abierta - es que fueron colocados en una visita posterior al sepulcro puede que con la intención de fijar el alma de esos difuntos a la tierra, quien sabe si para detener pesadillas nocturnas o algún tipo de sentimiento de culpa por... ¿una muerte prematura? 


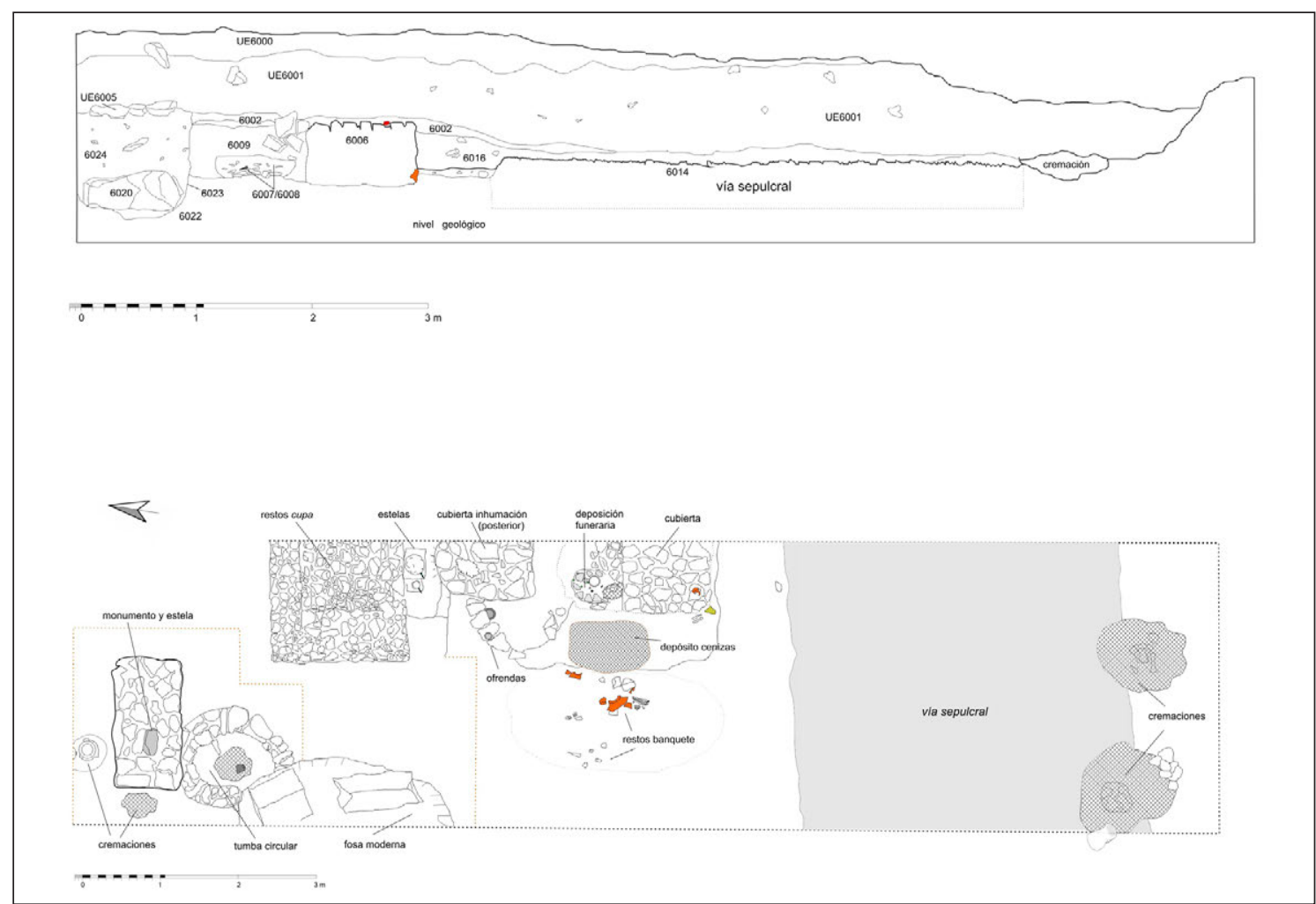

Figura 14. Arriba, perfil este (parcial) de la excavación de 2014. Debajo, la planta con indicación de los ítems comentados en el texto.

\section{CONSIDERACIONES FINALES}

Toda necrópolis, como toda ciudad, participa de rasgos universales y propios. No podemos por ello generalizar las lecturas ni buscar paralelos alejados tan solo por similitudes formales, pues los códigos cambian y difícilmente pueden ser los mismos. Por ello hay que ser riguroso en las descripciones, en la toma de datos y en la documentación, tratando de generar un registro que pueda ser de nuevo interpretado por investigadores, a la luz de otros datos o de nuevas líneas de análisis histórico (Fig. 14). Hemos de asumir la subjetividad propia de nuestra interpretación, así como que muchas de nuestras lecturas estarán envueltas en las estrategias de dominación social del presente. El análisis contextual implica un análisis social tanto como la relación entre el arqueólogo y su objeto de estudio, y más aún cuando se trata de un registro cargado de intencionalidad como es el funerario. Ya hemos apuntado que para determinados autores la conexión entre la identidad social y los elementos materiales habrá de ser necesariamente teórica ya que se trata de una percepción contemporánea. Aunque de las evidencias materiales se puedan inferir identidades diversas (género, edad o etnia, por ejemplo), esa inferencia estará sujeta a la propuesta del investigador.

Un buen número de elementos que se constatan en la necrópolis de Baelo no sobrevienen con la fundación de la ciudad hispanorromana ni mucho menos, algunos ya están instalados en la zona previamente, como se refleja en la necrópolis de la Silla del Papa (en lo que concierne, por ejemplo, al rito de cremación, a la existencia de monumentos funerarios de planta circular, al fenómeno del betilismo o a la presencia de piezas cerámicas triangulares en contacto con las deposiciones funerarias). Incluso la característica talla de figuras antropomorfas sobre la calcarenita local con rasgos negroides o gestos grotescos ya se documenta en la vecina necrópolis fenicio-púnica de la Isla de las Palomas de Tarifa (Prados et alii 2011).

Determinadas evidencias, que parecen generalizadas en el estado actual del conocimiento, sí son concluyentes y nos ayudan a caracterizar mejor las actitudes ante la muerte de los antiguos baelonenses: el uso exclusivo de la cremación hasta el s. III d. C., el hecho de que la vajilla empleada para el difunto sea exclusivamente para contener líquidos (generalmente jarras monoansadas de bocas estrechas y formas cerradas para beber, frecuentemente cerámica de pa- 
redes finas de los tipos más sencillos y arcaicos). En cambio encontramos fuera de la tumba terra sigillata gálica, y desde mediados del s. I, hispánica, que crece porcentualmente, en formas abiertas, óptimas para el consumo de sólidos (pero por parte de los vivos en el marco de las distintas ceremonias postdeposicionales); luego existe un universo de detalles, de pequeños objetos que aparecen como parte del ajuar pero a los que es imposible atribuir valores generales, al pertenecer al ámbito más íntimo del difunto y de su familia.

La dimensión social sí se manifiesta en la elección del tipo de tumba, alguna ciertamente monumental, y en aspectos tales como la celebración del banquete, el primer reflejo de un acto comunitario localizado y que refleja un comportamiento por parte de la elite y un interés en manifestar la "memoria pública" que proclama el prestigio del difunto y de su grupo a través del consumo de productos distinguidos (atún) y de la destrucción de vajillas finas. Se tratará, en definitiva, de la necrópolis de una ciudad levantada ex novo pero que consta de una élite local que quiso aparentar ser romana, pero que en la intimidad familiar reflejó también otros procesos, otras esperanzas y otras necesidades.

Esta comunidad local, al habitar una ciudad de frontera, abierta y portuaria, verá instalarse de forma paulatina nuevas gentes que irrumpirán con fuerza en la vida cotidiana y en la necrópolis, generando un horizonte "mestizo" en el que se fusionará el sustrato bástulo-púnico con la voluntad de alcanzar una vida "a la romana". Nuevas actitudes ante la muerte, nuevos ritos y una mayor variedad de monumentos (como las cupae) llegarán desde mediados del s. I (fig. 2). Junto al nuevo estatuto municipal otorgado por Claudio, las reformas y construcciones que se detectan en otros espacios de la ciudad como la basílica o el foro (Sillières 1997) afectarán también a la necrópolis (Prados et alii 2014; Prados 2015b). La construcción de la vía sepulcral (cubriendo enterramientos de las primeras fases) que la arqueología nos ha permitido fechar con firmeza en ese momento, será el nuevo eje vertebrador de la necrópolis y marcará la organización, tamaño y orientación de los nuevos sepulcros.

La vía y la nueva organización "urbana" de la ciudad de los muertos (véase de nuevo la fig. 1) será también la plasmación definitiva de la consecución del anhelo de los baelonenses de presentarse como nuevos romanos, en un espacio funerario tipificado y públicamente reconocible. Eso sí: tan solo el contexto arqueológico nos permitirá tratar de reconocer las identidades y profundizar en los sentimientos más íntimos, conservadores o no, de cada una de las familias que emplearon ininterrumpidamente esta isola sacra como cementerio durante más de tres siglos.

\section{BIBLIOGRAFÍA}

Alemán, A. 2013: "La problemática del litus maris en derecho romano y su problemática", Anuario da Facultade de Dereito da Universidade da Coruña, 17, 553-76.

Alfayé Villa, S. 2009: "Sit tibi terra gravis: magicalreligious practices against restless dead in the Ancient World", F. Marco, F. Pina y J. Remesal (eds.), Formae Mortis: el tránsito de la vida a la muerte en las sociedades antiguas, Col-lecció Instrumenta 30, Barcelona, 181-214.

Alfaro Giner, C. 2007: "Los entalles mágicos sobre piedras semipreciosas en el mundo antiguo: su técnica de fabricación y su significado", Magia y Superstición en el mundo fenicio-púnico. XXI Jornadas de Arqueología Fenicio-Púnica, Eivissa, 7-47.

Alonso, C., Ménanteau, L., Gracia, F. J. y Ojeda, R. 2007: "Geoarqueología y paleomorfología litoral de la ensenada de Bolonia. Primeros resultados y nuevas propuestas", A. Arévalo y D. Bernal (eds.), Las cetariae de Baelo Claudia. Avance de las investigaciones arqueológicas en el barrio meridional (2000-2004), Sevilla, 521-538.

Arévalo González, A. 2010: "Monedas para el Más Allá. Un primer acercamiento desde la necrópolis de Cádiz", A. M. Niveau y V. Gómez (coords.), Las necrópolis de Cádiz. Apuntes de Arqueología gaditana en homenaje a J. F. Sibón Olano, Cádiz, 507-527.

Arévalo González, A. y Bernal Casasola, D. (eds.) 2007: Las cetariae de Baelo Claudia. Avance de las investigaciones arqueológicas en el barrio meridional (2000-2004), Sevilla.

Arteaga, O. 1988: “Zur phönizischen Hafensituation von Toscanos. Vorberich über die Ausgrabungen in Schnitt 44", Forschungen zur Archäologie und Geologie im Raum von Torre del Mar 1983/84, Madrider Beitrage XIV, 127-141.

Bel, V., Blaizot, F., Bonnet, C., Gagnol, M. E., Georges, P., Gisclon, J. L., Lisfranc, R., Ricgier, A. et Wittman, A. 2009: "L'étape de la crémation : les bûchers funéraires", V. Blaizot (dir.), Pratiques et espaces funéraires de la Gaule durant l'Antiquité, Gallia 66.1, 89-174.

Bendala Galán, M. 2002: "Perduraciones y romanización en Hispania a la luz de la arqueología funeraria: notas para una discusión", Archivo Español de Arqueología, 75, 137-158. http://dx.doi. org/10.3989/aespa.2002.v75.132

Bendala Galán, M. 2010: "Baelo Claudia y su personalidad ciudadana y urbana: diálogo desde el estudio y la amistad", Pallas 82: Ab Aquitania in 
Hispaniam. Mélanges d'histoire et d'archéologie offerts à Pierre Sillières, 465-482.

Bendala Galán, M. 2012: "Elementos culturales neopúnicos en la Hispania antigua: historia e historiografía de un encuentro", B. Mora y G. Cruz (coords.), La etapa neopúnica en Hispania y el Mediterráneo centro occidental: identidades compartidas, Sevilla, 15-33.

Bendala Galán, M. 2015: "Morir en las ciudades hispanorromanas de la Bética. Perduraciones y romanización 40 años después", F. Prados y H. Jiménez (eds.), La muerte en Baelo Claudia. Necrópolis y ritual en el confín del Imperio romano, Alicante, 31-44.

Bernal Casasola, D. 2006: "La industria conservera romana en el «Círculo del Estrecho». Consideraciones sobre la geografía de la producción", A. Akerraz, P. Ruggeri, A. Siraj y C. Vismara (eds.), L'Africa romana. XVI Convegno Internazionale: Mobilità delle persone e dei popoli, dinamiche migratorie, emigrazioni ed immigrazioni nelle province occidentali dell'Impero romano Sassari, 1351-1394.

Bernal, D., Arévalo, A., Muñoz, A., Expósito, J. A., Díaz, J. J., Lagóstena, J., Vargas, J. M., Lara, M., Moreno, E., Sáez, A. M. y Bustamante, M. 2013: Las termas y el Suburbium marítimo de Baelo Claudia. Avance de un reciente descubrimiento", Onoba 1, 115-152.

Binford, L. 1971: "Archaeology of mortuary practices: their study and their potential", Memoirs of the Society for American Archaeology, 25, Approaches to the Social Dimensions of Mortuary Practices, 6-29.

Blaizot, F. 2009a: "L'image sociale et culturelle des pratiques funéraires : expressions et évolutions de la société romaine dans le sud-est de la Gaule "V. Blaizot (dir.), Pratiques et espaces funéraires de la Gaule durant l'Antiquité, Gallia 66, 1, 311-343.

Blaizot, F. (dir.) 2009b: Pratiques et espaces funéraires de la Gaule durant l'Antiquité, Gallia 66, 1 , Paris.

Blánquez Pérez, J., Jiménez Vialás, H. y Roldán Gómez, L. 2012: "Paisaje arqueológico - paisaje simbólico. Carteia y las Columnas de Hércules, una lectura comparada", F. Prados, I. García y G. Bernard (eds.), Confines. El extremo del mundo durante la Antigüedad, Alicante, 227-269.

Bonneville, J. N., Fincker, M., Sillières, P., Dardaine, S. y Labarthe, J. M. 2000: Belo VII. Le Capitole, Collection de la Casa de Velázquez 67, 2 vols., Madrid.

Bourgeois, A. y Del Amo, M. 1970: "La quatrième campagne de fouilles à Belo-Bolonia (Province de Cadix) en 1969", Mélanges de la Casa de Velázquez 6, 439- 456. http://dx.doi.org/10.3406/ casa.1970.1029

Carroll, M. 2013: "Ethnicity and Gender in Roman Funerary Commemoration. Case Studies from the Empire'es Frontiers", L. Nilsson-Stutz y S. Tarlow (eds.), The Oxford Handbook of the Archaeology of Death \& Burial, Oxford, 559-579. http://dx.doi. org/10.1093/oxfordhb/9780199569069.013.0031

Chapman, R. 2013: "Death, Burial and Social Representation", L. Nilsson-Stutz y S. Tarlow (eds.), The Oxford Handbook of the Archaeology of Death \& Burial, Oxford, 47-58. http://dx.doi.org/10.1093/ oxfordhb/9780199569069.013.0004

Ciurana, J. 2011: "Prácticas y rituales en las áreas funerarias del suburbio oriental de Tarraco", J. Andreu et alii (coords.), Mors omnibus instat. Aspectos arqueológicos, epigráficos y rituales de la muerte en el Occidente Romano, Madrid, 331-350.

Dardaine, S., Fincker, M., Lancha, J. y Sillières, P. 2007: Belo VIII. Le sanctuaire d'Isis, Collection de la Casa de Velázquez 107, 2 vols., Madrid.

De Larminat, S. 2012: "Le mobilier déposé dans les sépultures d'enfants en Afrique du Nord à l'époque romaine", A. Hermary y C. Dubois (eds.), L'Enfant et la mort dans l'Antiquité III. Le matériel associé aux tombes d'enfants, Aix en Provence, 293-312.

Denti, M. 2013: "Pour une Archéologie de l'Absence. Observations sur l'analyse intellectuelle et matérielle de la céramique en contexte rituel", M. Denti y M. Tuffreau-Libre (eds.), La céramique dans les contextes rituels. Fouiller et comprendre les gestes des anciens, Rennes, 13-23.

Fernández Vega, P. A. 1994: "Las áreas periurbanas de las ciudades altoimperiales romanas. Usos del suelo y zonas residenciales", Hispania Antiqua XVIII, 141-58.

Fowler, C. 2013: "Identities in transformation. Identities, Funerary Rites and the Mortuary Process", L. Nilsson-Stutz y S. Tarlow (eds.), The Oxford Handbook of the Archaeology of Death \& Burial, Oxford, 511-526. http://dx.doi.org/10.1093/oxfor$\mathrm{dhb} / 9780199569069.013 .0028$

García Jiménez, I. 2015: "Las otras necrópolis de Baelo Claudia”, F. Prados y H. Jiménez (eds.), La muerte en Baelo Claudia. Necrópolis y ritual en el confín occidental del Imperio, Alicante, 97-106.

Gómez Bellard, C. y Gómez Bellard, F. 1989: "Enterramientos infantiles en la Ibiza fenicio-púnica", Cuadernos de Prehistoria y Arqueología Castellonenses 14, 211-238.

Goodman, P. J. 2007: The Roman city and its periphery. From Rome to Gaul, Abingdon. 
Herrmann, B. 1976: "Neuere Ergebnisse zur Beurteilung menschlicher Brandknochen", Zeitschrift für Rechtmedizin 77, 191-200. http://dx.doi. org/10.1007/bf02114348

Hodder, I. (ed.) 1987: The Archaeology of Contextual Meanings, Cambridge.

Jiménez Díez, A. 2002: "Necrópolis de época republicana en el Mediodía peninsular: "Romanización" y sentimientos de identidad étnica", D. Vaquerizo (ed.), Espacios y usos funerarios en el Occidente Romano. Actas del Congreso Internacional celebrado en la Facultad de Filosofía y Letras de la Universidad de Córdoba vol. I, Córdoba, 217-231.

Jiménez Díez, A. 2007: "Culto a los ancestros en época romana: los cipos funerarios de las necrópolis de Baelo Claudia (Bolonia, Cádiz)", Archivo Español de Arqueología 80, 75-106. http://dx.doi. org/10.3989/aespa.2007.v80.28

Jiménez Díez, A. 2008: Imagines Hibridae. Una aproximación postcolonialista al estudio de las necrópolis de la Bética, Anejos de Archivo Español de Arqueología XLIII, Madrid.

Jiménez Vialás, H. 2015: "Paisajes de la muerte en las ciudades romanas del Estrecho. Necrópolis y espacios periurbanos altoimperiales", F. Prados y H. Jiménez (eds.), La muerte en Baelo Claudia. Necrópolis y ritual en el confín occidental del Imperio, Alicante, 65-80.

Lowenthal, D. 1985: The past is a foreign Country, Cambridge.

MacKinley, J. 1993: "Bone fragment size and weights of bone from modern British cremations and the implications for the pyre technology and ritual", Journal of Archaeological Science 21, 339-342. http://dx.doi.org/10.1006/jasc.1994.1033

Masi, C. 2014: "Litus maris: définition et controversies», E. Hermon y A. Watelet (dirs.), Riparia, un patrimoine culturel. La gestion intégrée des bords de l'eau. Proceedings of the Sudbury Workshop, April 12-14, 2012 / Actes de l'atelier Savoirs et pratiques de gestion intégrée des bords de l'eau - Riparia, Sudbury, 12 -14 avril 2012, Oxford, 233-242.

Mesa Hernández, E. y Niveau de Villedary y Mariñas, A. M. 2014: "Análisis arqueomalacológico de tres contextos rituales de la necrópolis púnica de Cádiz", Archaeofauna 23, 2014, 69-88.

Mischka, C. 2012: "A monument, lasting forever ?", M. Furholt, M. Hinz y D. Mischka (eds.), As time goes by? Monumentality, Landscapes and the Temporal Perspective. Socio-environmental Dynamics over the last 12000 years: The Creation of Landscapes II, Kiel, 233-244.
Mora Serrano, B. y Cruz Andreotti, B. (eds.) 2012: La etapa neopúnica en Hispania y el Mediterráneo centro-occidental: identidades compartidas, Sevilla.

Moret, P. y Prados Martínez, F. 2014: "Les deux Baelo: du site perché protohistorique au site portuaire romain sur la rive nord du détroit de Gibraltar", L. Mercuri et alii (eds.), Implantations humaines en milieu littoral méditerranéen (Actes des XXXI$V^{e s}$ Rencontres internationales d'archéologie et d'histoire d'Antibes), Nice, 137-148.

Morris, I. 1992: Death-Ritual and Social Structure in Classical Antiquity, Key Themes in Ancient History, Cambridge.

Nilsson Stutz, L. y Tarlow, S. 2013 (eds.): The Oxford Handbook of the Archaeology of Death \& Burial, Oxford.

Niveau de Villedary y Mariñas, A. M. 2004: “Ofrendas de peces y moluscos en la necrópolis púnica de Cádiz. Una aproximación”. I Conferencia Internacional sobre la Historia de la pesca en el ámbito del Estrecho, Cádiz, 601-632.

Niveau de Villedary y Mariñas, A. M. 2009: Ofrendas, banquetes y libaciones: el ritual funerario en la necrópolis púnica de Cádiz, Sevilla.

Paris, P., Bonsor, G., Laumonier, A., Ricard, R. y Mergelina, C. 1926: Fouilles de Belo (Bolonia, province de Cadix) (1917-1921). Tome II: La nécropole, Bibliothèque de l'École des Hautes Études Hispaniques, VI bis, Bordeaux.

Pearce, J. 2011: "Marking the Dead: Tombs and Topography in the Roman Provinces", M. Carroll y J. Rempel (eds.), Living Through the Dead. Burial and Commemoration in the Classical World, Studies in Funerary Archaeology 5, Oxford, 134-158.

Ponsich, M. 1988: Aceite de oliva y salazones de pescado. Factores geo-económicos de Bética y Tingitana, Madrid.

Prados Martínez, F. 2011: "La necrópolis oriental de Baelo Claudia (Tarifa, Cádiz) en el contexto de la religiosidad púnico-mauritana. Una lectura a partir de las últimas actuaciones arqueológicas", Zephyrus LXVIII, 191-210.

Prados Martínez, F. 2015a: “La Necrópolis Oriental de Baelo Claudia. Paisaje y arquitectura funerarios", F. Prados y H. Jiménez (eds.), La muerte en Baelo Claudia. Necrópolis y ritual en el confín occidental del Imperio, Alicante, 81-96.

Prados Martínez, F. 2015b: "El ritual funerario en Baelo Claudia durante el Alto Imperio (ss. I-II d. C.)", F. Prados y H. Jiménez (eds.), La muerte en Baelo Claudia. Necrópolis y ritual en el confín occidental del Imperio, Alicante, 107-124. 
Prados Martínez, F., García, I. y Castañeda, V. 2011: "El mundo funerario fenicio-púnico en el Campo de Gibraltar. Los casos de la necrópolis de Los Algarbes y la Isla de las Palomas (Tarifa, Cádiz)", E. Ferrer (coord.), Los púnicos de Iberia: proyectos, revisiones, síntesis, Mainake 2010, 32 (I), 251-278.

Prados Martínez, F., García, I. y Jiménez, H. 2014: "100 años de arqueología funeraria en Baelo Claudia. Avance de las nuevas investigaciones en la Necrópolis Oriental", Saguntum 46, 93-110. http:// dx.doi.org/10.7203/sagvntvm.46.3286

Prados Martínez, F. y Jiménez Vialás, H. (eds.) 2015: La muerte en Baelo Claudia. Necrópolis y ritual en el confín del Imperio romano, Alicante.

Prados Martínez, F., Muñoz, A., García, I. y Moret, P. 2012: "Bajar al mar y... ¿hacerse romano? De la Silla del Papa a Baelo Claudia”, B. Mora y G. Cruz (eds.), La etapa neopúnica en Hispania y el Mediterráneo centro-occidental: identidades compartidas, Sevilla, 301-329.

Rappaport, R. 1999: Ritual and Religion in the Making of Humanity, Cambridge.

Rascón García, C. y García González, J. M. 2011: Ley de las XII Tablas, Estudio preliminar, Madrid.

Remesal Rodríguez, J. 1979: La necrópolis sureste de Baelo, Excavaciones Arqueológicas en España 104, Madrid.

Roberts, C. 2013: "The Bioarchaeology of Health and Well-Being: Its Contribution to Understanding the Past", L. Nilsson-Stutz y S. Tarlow (eds.), The Oxford Handbook of the Archaeology of Death \& Burial, Oxford, 79-98. http://dx.doi.org/10.1093/ oxfordhb/9780199569069.013.0006

Ruiz Bueno, M. D. 2013: "La ruptura funeraria del pomerium desde su nacimiento y hasta su desaparición. Enterramientos in urbe", Onoba 1, 187-204.

Ruiz-Gálvez Priego, M. L. 1995: "Depósitos del Bronce Final: ¿sagrado o profano? ¿sagrado y, a la vez, profano?", M. L. Ruiz-Gálvez (ed.), Ritos de paso y puntos de paso. La Ría de Huelva en el mundo del Bronce Final Europeo, Complutum Extra 6, Madrid, 21-32.

Saxe, A. A. 1970: Social Dimensions of Mortuary Practices, Ph.D. University of Michigan, Michigan.

Seco Serra I. 2010: Piedras con alma. El betilismo en el mundo antiguo y sus manifestaciones en la Península Ibérica, SPAL Monografías XIII, Sevilla.

Scheid, J. 1998: La religion des romains, Paris.

Scheid, J. 2005: Quand faire, c'est croire: les rites sacrificiels des romains, Paris.

Sillières, P. 1997: Baelo Claudia. Una ciudad romana de la Bética, Madrid.
Tarlow, S. 2013: "Belief and the Archaeology of Death", L. Nilsson-Stutz y S. Tarlow (eds.), The Oxford Handbook of the Archaeology of Death \& Burial, Oxford, 617-630. http://dx.doi. org/10.1093/oxfordhb/9780199569069.013.0034

Toynbee, M.J. 1971: Death and burial in the Roman World, New York.

Tuffreau-Libre, M. 2013: "La céramique dans les sites funéraires et religieux de l'époque romaine. L'exemple de Porta Nocera à Pompei (Campanie, Italie)", M. Denti y M. Tuffreau-Libre (eds.), La céramique dans les contextes rituels. Fouiller et comprendre les gestes des anciens, Rennes, 167-178.

Vaquerizo Gil, D. (ed.) 2002: Espacios y usos funerarios en el Occidente romano: actas del Congreso Internacional celebrado en la Facultad de Filosofía y Letras de la Universidad de Córdoba (5-9 junio, 2001), 2 vols., Córdoba.

Vaquerizo Gil, D. 2008: "Figurative imagery of the deceased in the eastern necrópolis of Baelo Claudia (Baetica, Spain)", E. La Rocca, P. León y C. Parisi (eds.), Le due patrie acquisite. Studi di archeologia dedicate a Walter Trillmich, Roma, 418-434.

Vaquerizo Gil, D. 2010: Necrópolis urbanas en Baetica, Documenta, 15, Tarragona.

Vaquerizo Gil, D. 2011: "Espacios, usos y hábitos funerarios en la Hispania romana: reflexiones y últimas novedades", J. Andreu et alii (coords.), Mors omnibus instat. Aspectos arqueológicos, epigráficos y rituales de la muerte en el Occidente Romano, Madrid, 191-231.

Vaquerizo Gil, D. 2013: “Topography, monumentalization and funerary customs in urban necropoleis in Baetica", Journal of Roman Archaeology 26, 209-242. http://dx.doi.org/10.1017/ s1047759413000135

Van Dommelen, P. 2014: "Punic identities and modern perceptions in the western Mediterranean", J. Quinn y N. Vella (eds.), The Punic Mediterranean: identities and identification from Phoenician settlement to Roman rule, Cambridge, 42-57.

Zanker, P. 2000: "The city as symbol: Rome and the creation of an urban image", E. Fentress (ed.), Romanization and the city. Creations, transformations, and failures (Proceedings of a conference held at the American Academy in Rome, to celebrate the $50^{\text {th }}$ anniversary of the excavations at Cosa, 14-16 May, 1998, Journal of Roman Archaeology, Supplementary Series, 38, PortsmouthRhode Island, 25-41.

Recibido: 02-11-2015

Aceptado: 28-12-2015 